\title{
Inclusive plurals and the theory of number ${ }^{1}$
}

Luisa Martí

Queen Mary, University of London

Abstract. I argue that an account of both inclusive plurals (Dvorak and Sauerland 2006, Farkas and de Swart 2010, Grimm 2012, Ivlieva 2013, Krifka 1989, 1995, Mayr 2015, Lasersohn 1998, 2011, Sauerland 2003, Sauerland, Anderssen and Yatsushiro 2005, Spector 2007, Yatsushiro, Sauerland and Alexiadou 2017, Zweig 2009) and the crosslinguistic typology of grammatical number (Harbour 2014) requires the postulation of a [-atomic] feature (or something very much like it) in the structure of exclusive plural DPs. When combined with the only theory we currently have that accounts for the cross-linguistic typology of number, Harbour (2014), theories in which the exclusive plural DPs of a language with inclusive plurals are [-atomic]-less under-generate or over-generate with respect to that typology. These problems disappear as soon as the structure of exclusive plural DPs contains a component that generates exclusive plural interpretations, either Harbour's [-atomic] feature (added to a system with a second, [-atomic]-less structure, a proposal compatible with, e.g., Farkas and de Swart 2010), or a predicate-level exhaustivity operator (from Mayr 2015).

Keywords: grammatical number, inclusive plurals, dual, paucal, typology of number

\section{Introduction: semantics of plural count nouns}

The problem of inclusive plurals is illustrated in (1)-(2): plural forms of nouns in English, such as tomatoes, introduce into the interpretation ${ }^{2}$ only pluralities (or plural, or non-atomic individuals ${ }^{3}$ ) in examples such as $(1)^{4}$, but both singularities (or singular, or atomic individuals) and pluralities in examples such as (2) (from Sauerland 2003):

\section{(1) English \\ Lina harvested tomatoes}

(2) English

Lina didn't harvest tomatoes

For (1) to be true, Lina has to have harvested at least two tomatoes and is thus concerned with tomato pluralities each of which is constituted of two or more tomato

\footnotetext{
1 This work would have been literally impossible without the great generosity of a number of people. I want to thank, in particular, the tireless linguists who have shared their knowledge of (Ljubljana) Slovenian and/or their judgments with me: Lanko Marušič, Tatjana Marvin, Milena Sheppard and Rok Žaucer. Thanks also to Klaus Abels, Hagit Borer, Greville Corbett, Mary Dalrymple, Gabi Danon, Daniel Harbour, Clemens Mayr, Bruce Morén-Duolljá, Marisa Rivero, Jacopo Romoli, Christina Sevdali, Yasu Sudo, several anonymous reviewers and audiences at the 27th Colloquium in Generative Grammar in Alcalá de Henares, Spain, Ulster University at Jordanstown in Belfast, UK, and the Syntax and Semantics Reading Group at Queen Mary, University of London, for their help, their many questions and their comments, which have greatly improved my argument. All errors are of course mine.

${ }^{2}$ I use the term interpretation in the broadest possible sense, without making a commitment as to what mechanisms (syntactic, pragmatic, semantic) are involved in generating it.

${ }^{3}$ See Link (1983) and much subsequent work.

${ }^{4}$ At the very least when the example is interpreted purely episodically, not generically. The issue of genericity and kind interpretations is briefly taken up in section 4.1 .
} 
atoms. However, the negation of this sentence, in (2), requires Lina not to have harvested any tomatoes at all-neither one (a singularity) nor more than one (a plurality). If the plural form tomatoes in (2) introduced pluralities only, the sentence would be true in situations in which Lina harvested only one tomato (which does not constitute a plurality), contrary to fact. Plural forms such as tomatoes in (2) are known as inclusive plurals, since they include both singular and plural individuals. Exclusive plurals are plural forms that introduce only plural individuals. The issue is: what is the denotation of plural noun forms? Are plural forms always inclusive semantically? Are they ambiguous between an inclusive and an exclusive semantics? These questions, their answers, and their consequences have received a lot of attention in the literature (see Dvorak and Sauerland 2006, Farkas and de Swart 2010, Grimm 2012, Ivlieva 2013, Krifka 1989, 1995, Lasersohn 1998, 2011, Mayr 2015, Sauerland 2003, Sauerland, Anderssen and Yatsushiro 2005, Spector 2007, Yatsushiro, Sauerland and Alexiadou 2017, Zweig 2009, and Kiparsky and Tonhauser 2012 for an overview).

Harbour (2014) proposes a compositional theory of number that derives the cross-linguistic typology of grammatical number, that is, all and only the possible number systems in the languages of the world, from a small set of semantic and syntactic primitives. In his system, plural forms are unambiguously exclusive, and the problem of inclusive plurals arises. The main argument of this paper is that a proposal to solve the inclusive plurals problem that postulates unambiguously inclusive plural forms has problems of under- or over-generation when considered together with Harbour's proposal. Indeed, authors such as Dvorak and Sauerland (2006), Ivlieva (2013), Krifka (1989, 1995), Lasersohn (1998, 2011), Sauerland (2003), Sauerland, Anderssen and Yatsushiro (2005), Spector (2007), Yatsushiro, Sauerland and Alexiadou (2017), or Zweig (2009) have proposed that plural-marked DPs are semantically inclusive only, and argue that exclusive plural interpretations arise as a byproduct of independent, DP-unrelated mechanisms (sometimes, these are grammar-unrelated mechanisms as well) (I will call such systems inclusive-only systems from now on). The under-generation problem arises in languages that have number values such as dual or paucal, number values that are compositionally built on the semantically contentful, DPstructural feature [-atomic] in Harbour's system. An inclusive-only approach to inclusive plurals predicts that such languages cannot have inclusive plurals, contrary to fact. Certain versions of the inclusive-only account are shown to have the opposite problem, a problem of over-generation, whereby unattested number systems, such as one that distinguishes only singular from dual, are incorrectly predicted to exist.

An alternative solution is to assume that plural forms are ambiguous between an exclusive and an inclusive semantics, as argued for, for example, in Farkas and de Swart (2010). Combined with Harbour, this type of approach entails that a [-atomic] feature in the structure of exclusive plural DPs is responsible for exclusivity, and, I suggest, absence of number (NumP) in the structure of inclusive plural DPs is responsible for inclusivity. An advantage of this approach is that inclusive plurals can be subsumed under general number, a number distinction that some languages express overtly as a separate number category, as shown in Corbett (2000), thus removing part of the stipulative nature of Farkas and de Swart's proposal. Because this solution retains the mechanism for the generation of dual and paucal number values, namely, [-atomic], and an independent solution to the inclusive plurals problem is provided, the under- and over-generation problems of the inclusive-only approaches disappear. Another way to avoid these problems is to use a predicate-level exhaustivity operator, instead of 
[-atomic], in the structure of exclusive plural DPs, as proposed in Mayr (2015), a possibility I discuss as well.

The empirical focus of the paper is on the semantics of common, count nouns (more specifically, bare plurals). Of course, pronouns, and other categories that go beyond the nominal domain, such as verbs, may also display grammatical number (see Corbett 2000 for many illustrations, in many languages). Pronouns are special, since, typically, languages display grammatical number on them, and Harbour's theory of number draws heavily on pronominal paradigms. While nothing in what I say here suggests that pronouns should be excluded from consideration, reasons of space and of access to native speakers of the relevant languages prevent me from systematically studying their interpretation in this paper. For example, I will not draw firm conclusions about the existence of inclusive plural pronoun forms (but see Harbour 2016: 149-152 for some discussion).

My argument is independent of the particular mechanism that inclusive-only approaches might use to derive exclusive plural interpretations (e.g., Maximize Presupposition, DP-unrelated exhaustivity operators/higher-order implicatures, etc.), and the status of number information in the semantics of features (presupposition vs. entailment). While the proper explanation of certain well-known, recalcitrant problems in the inclusive plurals literature (such as the problem of non-monotonic environments, e.g., Exactly one student read books) might be an issue for some theories that do use DPstructural means for the derivation of exclusive plural interpretations, these issues are orthogonal to the argument presented in this paper. For example, some inclusive-only approaches, such as Spector (2007), have solutions for the problem of non-monotonic environments but are subject to the criticism presented here. On the other hand, some non-inclusive-only approaches, such as Farkas and de Swart (2010), do not have a solution for the problem of non-monotonic environments but are not subject to the criticism presented here. My goal here is to bring to light ways in which the crosslinguistic typology of grammatical number may inform the debate on the correct account of inclusive plurals.

The paper is organized as follows. Section 2 introduces the basics of Harbour (2014). Section 3 discusses the problem of inclusive plurals as it arises in this theory and provides arguments against solving it by postulating that exclusive plural DPs in languages with inclusive plurals are not exclusive semantically. Section 4 shows that ambiguity approaches, that is, those in which plural DPs are ambiguous between an exclusive, [-atomic] semantics and an inclusive semantics, do not suffer from these problems as a matter of principle. Neither does replacing [-atomic] with Mayr's (2015) predicative-level exhaustivity operator. Section 5 concludes.

\section{Harbour (2014)}

It is well-known that languages make grammatical number distinctions that go beyond singular and plural: one can find number inflection for dual, trial, minimal, augmented, paucal, or greater plural, among others, as discussed in Corbett's (2000) seminal typological study of number systems. I will illustrate here with languages that contain duals and/or paucals in addition to singular and plural, as these will be the most relevant for us later on. The reader is referred to Corbett (2000) and Harbour (2011, 2014) for detailed discussion of other number values. 
Consider Ljubljana Slovenian, a dialect of Slovenian spoken in and around Ljubljana. As shown in the (partial ${ }^{5}$ ) paradigm of noun inflection in Table 1, Ljubljana Slovenian distinguishes singular, dual and plural. These distinctions are most noticeable in the masculine declension, with a significant amount of syncretism of the dual with the plural in the feminine and neuter declensions (Rok Žaucer, p.c.; for standard Slovenian, see Derganc 2003, Herrity 2016, Marušič and Žaucer to appear, Toporišič 2000):

\begin{tabular}{|l|l|l|l|l|l|l|l|}
\hline & & NOM & ACC & GEN & LOCATIVE & DATIVE & INSTRUMENTAL \\
\hline MASC & SING & stol & stol & stola & pri stolu & stolu & s stolom \\
stol & DUAL & stola & stola & stolov & pri stolih & stolom(a) & s stoloma/s stoli \\
'chair' & PLURAL & stoli & stole & stolov & pri stolih & stolom & s stoli \\
\hline FEM & SING & hiša & hišo & hiše & pri hiši & hiši & s hišo \\
hiša & DUAL & hiše & hiše & hiš & pri hišah & hišam(a) & s hišama/s hišami \\
'house' & PLURAL & hiše & hiše & hiš & pri hišah & hišam & s hišami \\
\hline NEUT & SING & mest & mest & mesta & pri mestu & mestu & z mestom \\
mesto & DUAL & mesta & mesta & mest & pri mestih & mestom(a) & z mestoma/z mesti \\
'town' & PLURAL & mesta & mesta & mest & pri mestih & mestom & z mesti \\
\hline
\end{tabular}

Table 1 Ljubljana Slovenian nouns

The dual is being lost in southern dialects of Slovenian, though it is still robust in central and northern dialects (see Marušič and Žaucer to appear for more discussion). Signs that the dual is robust in Ljubljana Slovenian are that it is part of the regular inflectional paradigm of nouns (i.e., it is not restricted to just a few nouns) and that it displays its own dual agreement patterns with other elements (adjectives, verbs, etc.) ${ }^{6,7}$.

Some languages have a grammatical number value of paucal. Paucal forms are used when the number of real-world entities concerned is small in number. Consider the number system of Bayso, a Cushitic language spoken in Ethiopia, whose nouns distinguish singular, paucal and plural (Corbett 2000, 2012: 224-33, Corbett and Hayward 1978, Hayward 1979)(in addition to general number, discussed in section 4):

\footnotetext{
5 There is a second declension for feminine nouns which is not shown here.

6 The plural-syncretic nominative dual forms trigger obligatory dual subject-verb agreement, as shown in (i), so, featurally, they are separate dual forms (Rok Žaucer, p.c.):
}

(i) Ljubljana Slovenian

$\begin{array}{lll}\text { Dve } & \text { rože } & \text { cvetita/*cvetijo } \\ \text { Two. NOM.FEM.DU } & \text { flower.NOM.FEM.DU } & \text { blossom.3DU/blossom.3PL } \\ \text { '(The) two flowers are blossoming' } & \end{array}$

(ii) Ljubljana Slovenian
Tri rože
cvetijo
Three.NOM.FEM.PL flower.NOM.FEM.PL
blossom.3PL

'(The) three flowers are blossoming'

${ }^{7}$ Key to abbreviations in glosses: 1 = first person; $2=$ second person; $3=$ third person; ACC = accusative case; $\mathrm{ANIM}=$ animate; $\mathrm{AUX}=$ auxiliary; $\mathrm{DAT}$ = dative case; $\mathrm{DEF}=$ definite; $\mathrm{DEM}=$ demonstrative; $\mathrm{DU}=$ dual; $\mathrm{FEM}=$ feminine; GEN = genitive case; GENERAL = general number; INANIM = inanimate; INDEF = indefinite; INTRAN = intransitive; $\mathrm{MASC}=$ masculine; $\mathrm{NEG}=$ negation; $\mathrm{NEUT}=$ neuter; $\mathrm{NOM}=$ nominative case $; \mathrm{PAST}=$ past tense; PAUC = paucal $;$ PL = plural; POSS = possessive; PREP = preposition; PRES = present; PRON $=$ pronoun; PTC = particple; $\mathrm{Q}=$ question operator; $\mathrm{SG}=$ singular; $\mathrm{TRAN}=$ transitive. 


\begin{tabular}{|l|l|l|l|}
\hline & SINGULAR & PAUCAL & PLURAL \\
\hline lion & lubántiti & lubanjaa & lubanjool \\
\hline bull & áartiti & aaraajaa & aaraar \\
\hline sister & abbati & abbajaa & abbalaal \\
\hline bird & kimbírtiti & kimbirjaa & kimbirjool \\
\hline ear & nebeti & nebejaa & nebebboo \\
\hline
\end{tabular}

Table 2 Bayso nouns

Paucal forms, such as lubanjaa 'lion.PAUc' in (3)b, indicate that a small number of lions is involved, from two to about six (Corbett 2000: 22) (verbal agreement for the paucal is in the plural; this agreement pattern is found with plural pronouns as well):

(3) Bayso
a. Lubán-titi hudure
lion-SG sleep.MASC.SG.PAST
'A single/particular lion slept'
b. Luban-jaa hudureene
lion-PAUC sleep.PL.PAST
'A few lions slept'
c. Luban-jool hudure
lion-PL sleep.MASC.SG.PAST
'Lions slept'

Paucal is an approximative number: how many lions are said to be sleeping in an example like (3)b may vary slightly from speaker to speaker or from situation to situation (e.g., for some speakers, the upper bound may not be six but five, etc.; cf. English a few).

Consider also Biak, an Austronesian language spoken in Indonesia, which distinguishes singular, dual, paucal and plural on verbal agreement markers, determiners, demonstratives, and possessive pronouns, as shown in Dalrymple and Mofu (2013). Table 3 shows the number distinctions made on (proximal) demonstratives and definite determiners in this language:

\begin{tabular}{|l|l|l|l|l|l|}
\hline & SINGULAR & DUAL & PAUCAL & PLURAL (ANIM) & PLURAL (INANIM) \\
\hline $\begin{array}{l}\text { Proximal } \\
\text { demonstrative }\end{array}$ & ine & suine & skoine & sine & na(i)ne \\
\hline $\begin{array}{l}\text { Definite } \\
\text { determiner }\end{array}$ & i/ya & sui/suya & skoi/skoya & si/sya & na \\
\hline
\end{tabular}

Table 3 Biak demonstratives and definite determiners

Even though Biak nouns themselves do not (overtly) mark these distinctions, elements that accompany them in the noun phrase do. (4) provides some examples (from Dalrymple and Mofu 2013: 45)(the range of the paucal starts at three and may go up to about ten; Mary Dalrymple, p.c.): 
(4) Biak

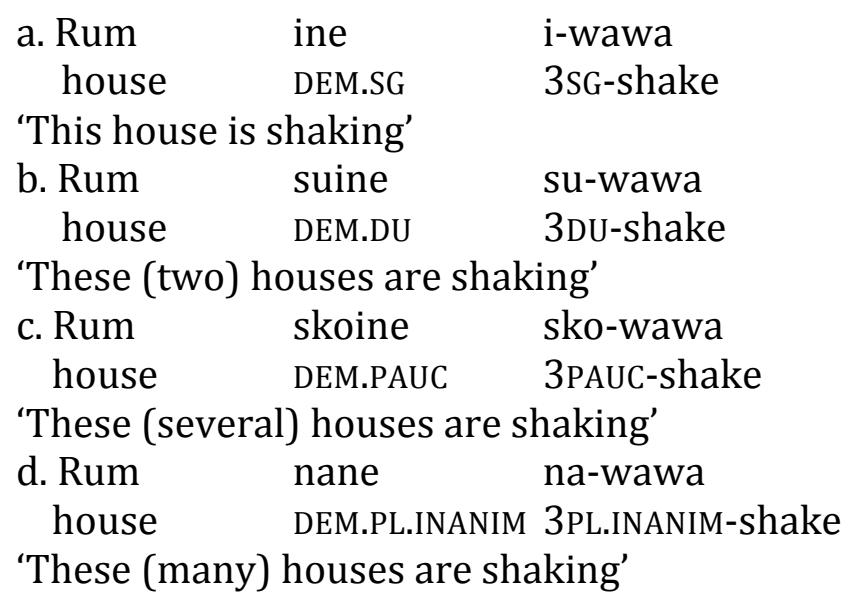

In addition to the systems here exemplified, the cross-linguistic typology of number includes languages with no number (Pirahã, Everett 1986: 217, Corbett 2000: 50-1; Dëne Sųłiné, Wilhelm 2008), singular-dual-lesser paucal-greater paucal-plural systems (e.g., Sursurunga, Corbett 2000: 26-30; cf. Hutchisson 1986), singular-dual-trial-paucalplural systems (e.g., Marshallese), minimal-augmented systems (e.g., Winnebago), and others (for more, see Harbour 2014 and references cited there). However, there are no attested number systems that distinguish, for example, just singular from dual, or paucal from plural, or trial from plural, or trial from paucal. The full set of crosslinguistic generalizations is in (5) (cf. Greenberg 1966):

(5) Trial requires dual

Dual requires singular

Singular requires plural

Plural requires singular or minimal

Unit augmented requires augmented

Minimal requires augmented or plural

Augmented requires minimal

Greater paucal requires (lesser) paucal

Paucal requires plural

Greater (and global) plural requires plural or augmented

The challenge for a theory of number whose goal is to account for the cross-linguistic typology of number is to explain the important fact that, as (5) shows, not all logically possible number value combinations constitute possible number systems. Harbour's (2014) theory postulates the smallest number of primitives/features that derive the possible number systems while explaining why the impossible systems are impossible, that is, that derive the generalizations in (5). It also provides the basis on which to explain the morpho-phonological and morpho-syntactic realization of features in different languages. His main assumptions are as follows: (a) NumP takes $\mathrm{nP}$ as complement, as in (6), (b) $\mathrm{n}^{0}$ assigns roots to the category of nouns and structures them into semilattices, (c) only three features can appear in Num ${ }^{0}$ : [ \pm additive], [ \pm atomic], [ \pm minimal], as in (6), (d) these features operate on the lattices provided by $\mathrm{nP},(\mathrm{e})$ the repetition of a particular feature in $\mathrm{Num}^{0}$ may or may not be allowed in a language, and (f) the semantic range of the [ \pm additive] cut is subject to social convention. We will consider assumptions (a)-(d) and (f) in what follows (assumption (e) is necessary to 
derive number values like minimal, augmented, unit augmented, trial, lesser and greater paucals, and others; see Harbour 2011, 2014 for more details). Assumptions (a), (b) and (d) are quite commonly made in the literature: ${ }^{8}$

(6)

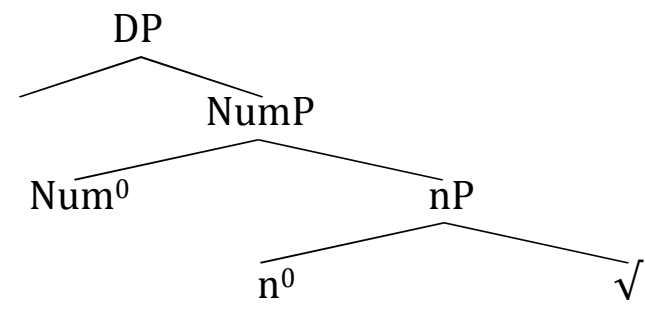

Assuming a simplified model with just three individuals in it, $\mathrm{a}, \mathrm{b}$ and $\mathrm{c}$, what $\mathrm{n}^{0}$ is taken to do to roots is to structure them into the join semilattice in (7):

(7)

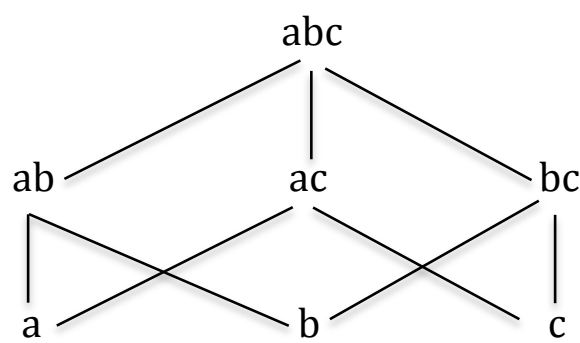

Equivalently:

(8) $[[n P]]=\{a, b, c, a b, a c, b c, a b c\}$

The semantics for the number features is assumed to be as follows ${ }^{9}$ :

(9) $[[$ +atomic $]]=\lambda P . \lambda x . P(x) \&$ atom $(x)$

$[[-$ atomic $]]=\lambda P . \lambda x . P(x) \& \neg$ atom $(x)$

(10) $[[+$ minimal $]]=\lambda P . \lambda x . P(x) \& \neg \exists y P(y) \& y \sqsubset x$

$[[-$ minimal $]]=\lambda P . \lambda x . P(x) \& \exists y P(y) \& y \sqsubset x$

(11) $[[$ +additive $]]=\lambda P . \lambda x . Q(x) \& Q \sqsubset P \& \forall y Q(y) \rightarrow Q(x \sqcup y)$

$[[$-additive $]]=\lambda P . \lambda x . Q(x) \& Q \subset P \& \neg \forall y \quad Q(y) \rightarrow Q(x \sqcup y)$

[ \pm Atomic] is sensitive to atoms/singularities ([+atomic]) vs. non-atoms/pluralities ([-atomic $])$. [ \pm Minimal] is sensitive to elements with parts $([-$ minimal $])$ vs. elements without parts $([+$ minimal $])$. [ \pm Additive] is concerned with whether the output set

\footnotetext{
8 Other syntactic projections inside DP are of course possible, but they are irrelevant for my purposes.

${ }^{9}$ I deviate from Harbour in that I treat the contribution of the number features to be entirely made up of entailments, whereas for him some of their content is presupposed. Nothing of what I say here depends on this. [ \pm Atomic] is of type $<\mathrm{e}, \mathrm{t}>$, not $<\mathrm{et}$, et $>$, in his proposal, but, again, the difference is not important here. Lower case variable names range over both atomic and non-atomic individuals. $\sqsubset$ is the proper subpart relation. In the denotation for [ \pm additive], in (11), $\mathrm{Q}$ is a free variable and $\sqcup$ is the join operation. It is not entirely clear in Harbour (2014) why there is a need to use a free variable $Q$ in the denotation of [ \pm additive]. [+Additive] returns as output a proper subset $\mathrm{Q}$ of $\mathrm{P}$ which contains the join of any two elements, [-additive] returns a proper subset which does not.
} 
contains, for any two of its members, their join ([+additive]) (a property also known as cumulativity; cf. Krifka 1989) or not ([-additive]).

Let's start by considering a simple singular-plural system. Such a system allows only (12) and (13), that is, the only features that can appear in $\mathrm{Num}^{0}$ are [ \pm atomic]:
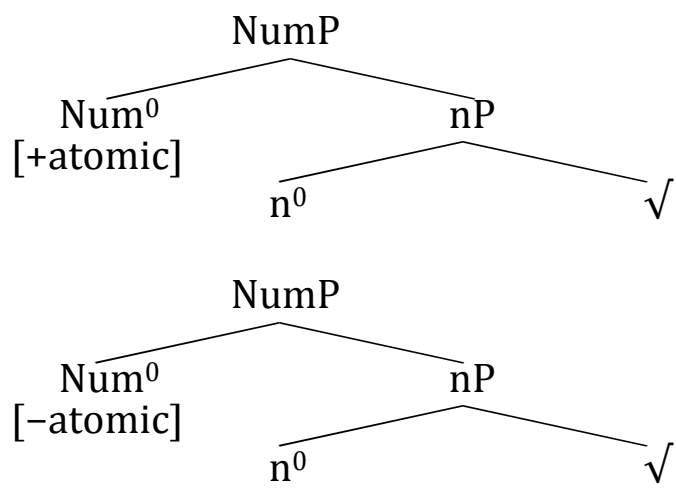

(14) gives rise to a singular semantics, and (15), to a strictly plural semantics ${ }^{10,11:}$

(14) $[[(12)]]=[[\mathrm{NumP}]]=[[+$ atomic $]]([[\mathrm{nP}]])=\lambda \mathrm{x} .[[\mathrm{nP}]](\mathrm{x}) \&$ atom $(\mathrm{x})$

(15) $[[(13)]]=[[$ NumP $]]=[[-$ atomic $]]([[n P]])=\lambda x \cdot[[n P]](x) \&$ atom $(x)$

Importantly, the structure that gives rise to (15), i.e., to exclusive plural interpretations, contains a [-atomic] feature. In English, [+atomic] is not morphologically realized overtly, but [-atomic] is, as $-s$.

As Harbour (2011) observes, the same result is obtained if a system allows just [ \pm minimal] in $\mathrm{Num}^{0}$ (and does not allow repetition of features, (e)), since the set of elements in (7) that have no subparts ([+minimal]) coincides with the set of atoms ([+atomic $]$ ), and the set of elements in (7) that have subparts ([-minimal]) coincides with the set of non-atoms ([-atomic]). Thus, there might be cases where it is not possible to distinguish [ \pm minimal] from [ \pm atomic]. However, there are cases in which the two do come apart. One such case is provided by systems with dual number, such as Ljubljana Slovenian, which are argued to use both [ \pm atomic] and [ \pm minimal] in Num ${ }^{0}$. Consider the following feature combinations (cf. Noyer 1992, Harbour 2011):

\footnotetext{
${ }^{10}$ Given the semantics of [ \pm atomic], it will not be possible to repeat this feature, as per (e), since nothing can satisfy (i):

(i) $[[+$ atomic $]]([[-$ atomic $]]([[\mathrm{nP}]]))=[[-$ atomic $]]([[+$ atomic $]]([[\mathrm{nP}]]))=\lambda \mathrm{x} \cdot[[\mathrm{nP}]](\mathrm{x}) \&$ atom $(\mathrm{x}) \&$ atom $(\mathrm{x})$

Footnotes 12 and 13 provide some detail into the workings of assumption (e).

${ }^{11}$ Harbour is not explicit as to how van Benthem's problem (van Benthem 1986) might be addressed in his system. The problem can be seen to arise in e.g., (i):

(i) $[$ [A dog is barking] $]=1$ iff $\exists x \operatorname{dog}(x) \&$ atom(x) \& is_barking(x)

If (i) is correct and all there is to say about the English sentence $A$ dog is barking, then that sentence is predicted to be compatible with a situation in which many dogs are barking and equivalent to One or more dogs are barking, which does not seem intuitively correct. This suggests that the denotation of indefinites is more involved than mere existential quantification would suggest, or that there are further processes at work that exclude the unwanted situations. The problem will arise for nouns marked for numbers other than plural. I cannot decide this matter here.
} 
(16) a. $[[+$ minimal $]]([[+$ atomic $]]([[\mathrm{nP}]]))=$

$=\lambda x .[[\mathrm{nP}]](\mathrm{x}) \&$ atom $(\mathrm{x}) \& \neg \exists \mathrm{y}$ atom $(\mathrm{y}) \& \mathrm{y} \subset \mathrm{x}$

b. $[[+$ minimal $]]([[-$ atomic $]]([[\mathrm{nP}]]))=$

(singular)

$=\lambda \mathrm{x} .[[\mathrm{nP}]](\mathrm{x}) \&$ ᄀatom $(\mathrm{x}) \& \neg \exists \mathrm{y}$ ᄀatom $(\mathrm{y}) \& \mathrm{y} \subset \mathrm{x}$

(dual)

c. $[[-$ minimal $]]([[-$ atomic $]]([[\mathrm{nP}]]))=$

(plural)

$=\lambda \mathrm{x} \cdot[[\mathrm{nP}]](\mathrm{x}) \&$ atom $(\mathrm{x}) \& \exists \mathrm{y}$ ᄀatom(y) \& yᄃx

d. \#[[-minimal $]]([[+$ atomic $]]([[\mathrm{nP}]]))=$

$=\lambda \mathrm{x} .[[\mathrm{nP}]](\mathrm{x}) \&$ atom $(\mathrm{x}) \& \exists \mathrm{y}$ atom $(\mathrm{y}) \& \mathrm{y} \sqsubset \mathrm{x}$

The feature combination in (16)a yields the singular number value. Both (16)b and (16)c will be crucial for us: (16)b yields the dual number value (informally, [-atomic] eliminates the atoms, and [+minimal] chooses the bottommost layer of the lattice after that, which is constituted by all the pluralities constituted of two atoms). (16)c yields plural (for more than two referents). Since nothing can satisfy (16)d (atoms do not have atoms as proper parts), (16)d does not give rise to a number value. ${ }^{12,13}$

This decompositional analysis of the dual into [-atomic] and [+minimal] is attractive for a number of reasons. First, there is no need to postulate a primitive feature [DUAL]. Instead, the derivation of this number value is achieved by features, [+minimal] and [-atomic], that are justified separately elsewhere (for more on [+minimal], see Harbour 2011 and footnotes 12 and 13). This in turn means that the implicational universals in (5) concerned with the dual follow from the fact that the feature [-atomic] is used. Those universals say that there is no language with a dual that doesn't also have singular and plural. If [-atomic] is used for the dual, then other numbers that make use of this feature value, such as plural, must also be present in the system, and if [-atomic] is used, then [+atomic] is used too, which is involved in the singular. Patterns of morphological realization and agreement in different languages can also be explained (see Noyer 1992 and Harbour 2014 for examples). That dual is mastered later than plural in first language acquisition, and that it can be lost without losing the plural, also follow in this approach (see Nevins 2011 for more discussion). The compositional account of these generalisations within Harbour's system will play an important role in my arguments in section 3.

\footnotetext{
12 Another such case is provided by systems that make a distinction between first person inclusive (the combination of speaker and hearer) and first person exclusive (just the speaker). In these systems, $[+$ minimal $](\mathrm{P}) \neq[+$ atomic $](\mathrm{P})$, for the combination of speaker and hearer is not an atom but constitutes the most minimal element that can be chosen from the speaker-hearer combination. Minimal-augmented systems like that of Winnebago, a Siouan language spoken in the US (Noyer 1992, Harbour 2011), and minimal-unit augmented-augmented systems like that of Rembarrnga, a Northern Australian language (Corbett 2000: 166, Harbour 2011, McKay 1978), make use of [ \pm minimal], and Rembarrnga allows its repetition $((\mathrm{e}))$.

13 Consider also the trial. This is a number value that arises in systems that use both [ \pm minimal] and [ \pm atomic], and where [ \pm minimal] is allowed to repeat (assumption (e)). Such a system gives rise to four well-formed feature combinations and two ill-formed ones. The four well-formed combinations yield singular, dual, trial and plural. Trial is derived as follows:
}

(i) $[[+$ minimal $]]([[-$ minimal $]]([[-$ atomic $]]([[\mathrm{nP}]])))=$

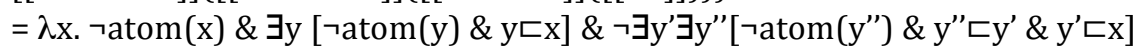

(i) is the set of all elements $x$ for which all subelements y" of subelements $y^{\prime}$ are atomic-this is only satisfied for elements $\mathrm{x}$ that are constituted of exactly three atoms, and trial number is derived. The fact that trial requires dual $((5))$ follows from the fact that the dual is generated with a subset of the features used for the trial ([+minimal] and [-atomic], as in (16)b). 
Paucals are derived using the feature [ \pm additive], which is subject to the additional constraint ((f) above) that its semantic range is subject to social convention. Let's consider the simplest system that contains a paucal, a [ \pm additive, \pm atomic] system, exemplified by Bayso above:

(17) a. $[[$-additive $]]([[+$ atomic $]]([[\mathrm{nP}]])=$

$=\lambda \mathrm{x} . \mathrm{Q}(\mathrm{x}) \& \mathrm{Q} \sqsubset[[+$ atomic $]]([[\mathrm{nP}]]) \& \neg \forall \mathrm{y} \mathrm{Q}(\mathrm{y}) \rightarrow \mathrm{Q}(\mathrm{x} \sqcup \mathrm{y})$

b. $[[$-additive $]]([[-$ atomic $]]([[\mathrm{nP}]]))=$

(singular)

$=\lambda \mathrm{x} . \mathrm{Q}(\mathrm{x}) \& \mathrm{Q} \subset[[$-atomic $]]([[\mathrm{nP}]]) \& \neg \forall \mathrm{y} \mathrm{Q}(\mathrm{y}) \rightarrow \mathrm{Q}(\mathrm{x} \sqcup \mathrm{y})$

c. $[[$ +additive $]]([[-$ atomic $]]([[\mathrm{nP}]]))=$

$=\lambda \mathrm{x} . \mathrm{Q}(\mathrm{x}) \& \mathrm{Q} \subset[[-$ atomic $]]([[\mathrm{nP}]]) \& \forall \mathrm{y} \mathrm{Q}(\mathrm{y}) \rightarrow \mathrm{Q}(\mathrm{x} \sqcup \mathrm{y})$

d. $\#[[$ +additive $]]([[+$ atomic $]]([[\mathrm{nP}]]))=$

$=\lambda \mathrm{x} . \mathrm{Q}(\mathrm{x}) \& \mathrm{Q} \sqsubset[[+$ atomic $]]([[\mathrm{nP}]]) \& \forall \mathrm{y} Q(\mathrm{y}) \rightarrow \mathrm{Q}(\mathrm{x} \sqcup \mathrm{y})$

(paucal)

(plural)

[ \pm Additive] is defined with reference to a proper subset $Q$ of the characteristic set of the function denoted by its input. (17)a yields singular number. It denotes the set of atomic elements $\mathrm{x}$ in $\mathrm{Q}$ such that for not all combinations of $\mathrm{x}$ with other elements $\mathrm{y}$ is it the case that their join is in Q. Constraint (f) is not particularly evident in this feature combination because [+atomic] alone already characterizes the set of atoms. But it is more in evidence in (17)b, which yields paucal number. (17)b denotes the set of nonatomic elements $\mathrm{x}$ in $\mathrm{Q}$ such that for not all combinations with other elements $\mathrm{y}$ is it the case that their join is in $\mathrm{Q}$. The semantic range of the [-additive] cut is subject to social convention, and this means that the size of $Q$ might vary from speaker to speaker (or from community of speakers to community of speakers). This is as it should be, for paucal number is an approximative number, not an exact number-its approximative nature is well documented in the literature (see Corbett 2000 for more). If the cut for this feature is relatively low, the paucal thus generated will be concerned with a small number of real-world entities, perhaps between two and five. Not all speakers of this language might agree, as per (f), and some may set the upper limit at, e.g., six. (17)c yields plural number (more on the semantics of the plural in languages with paucals in section 4.2). (17)d yields no number value, as a set of atoms cannot be cumulative. Paucal number is not postulated as a primitive [PAUCAL]. This again has the advantage of allowing us to explain universals about paucal number. For example, there is no language that has paucal number without also having plural number-this follows from the fact that the feature [-atomic] is used in deriving both the plural and the paucal, but the paucal requires an additional ingredient, [-additive $]^{14}$.

Consider, finally, the possibility that a language might make use of the three features [ \pm additive], $[ \pm$ minimal] and $[ \pm$ atomic]. Such a system gives rise to the following number distinctions:

(18) a. $[[$-additive $]]([[+$ minimal $]]([[+$ atomic $]]([[\mathrm{nP}]])))=$

$=\lambda \mathrm{x} . \mathrm{Q}(\mathrm{x}) \& \mathrm{Q} \subset[[[+$ minimal $]]([[+$ atomic $]]([[\mathrm{nP}]])) \& \neg \forall \mathrm{y} Q(\mathrm{y}) \rightarrow \mathrm{Q}(\mathrm{x} \sqcup \mathrm{y})$

b. $[[$-additive $]]([[+$ minimal $]]([[-$ atomic $]]([[\mathrm{nP}]])))=$

$=\lambda x . Q(x) \& Q \subset[[+$ minimal $]]([[-$ atomic $]]([[\mathrm{nP}]])) \& \neg \forall \mathrm{y} Q(y) \rightarrow Q(x \sqcup y)$

(singular)

${ }^{14}$ Cuts for [ \pm additive] that are relatively high will give rise to other approximative number values, such as greater plurals. The feature [ \pm additive] is argued in Harbour (2014: 196-7) to be subject to further constraints, e.g., only horizontal cuts of certain kinds are allowed. 
c. $[[$-additive $]]([[-$ minimal $]]([[$-atomic $]]([[\mathrm{nP}]])))=$

$=\lambda \mathrm{x} . \mathrm{Q}(\mathrm{x}) \& \mathrm{Q} \subset[[-$ minimal $]]([[-$ atomic $]]([[\mathrm{nP}]])) \& \neg \forall \mathrm{y} \mathrm{Q}(\mathrm{y}) \rightarrow \mathrm{Q}(\mathrm{x} \sqcup \mathrm{y})$

d. $[[$ +additive $]]([[-$ minimal $]]([[-$ atomic $]]([[\mathrm{nP}]])))=$

$=\lambda \mathrm{x} . \mathrm{Q}(\mathrm{x}) \& \mathrm{Q} \subset[[[-$ minimal $]]([[-$ atomic $]]([[\mathrm{nP}]])) \& \forall \mathrm{y} \mathrm{Q}(\mathrm{y}) \rightarrow \mathrm{Q}(\mathrm{x} \sqcup \mathrm{y})$

Indeed, Biak, as described in section 1, is such a number system (feature combinations not shown in (18) yield no number values), with the cut for [ \pm additive] conventionally set to low. A difference between Biak and other number systems we've seen before is that the locus of the morpho-phonological realization of number features is not on nouns but on other elements in this language, in the noun phrase or elsewhere.

Additional possible and impossible number values and number systems follow from the basics of the theory as presented here.

Importantly, we have seen that in this theory [-atomic] is used not only in the derivation of plurals but also in the derivation of duals and paucals (in addition to trials, see footnote 13). Plural number here is always at least [-atomic], and sometimes a combination of [-atomic] with other features. This entails variation in the range of the plural-e.g., in a singular-dual-plural system, plural number arises from [-minimal, -atomic] and is thus for three or more real-world entities. In a language in which plural number is just [-atomic], that is, in a singular-plural system, the plural is predicted to be concerned with two or more real-world entities. While it is in fact empirically the case that not all plurals are created equal, the semantic range of the plural goes beyond what is predicted by Harbour, as in some languages and in some contexts, plurals can even be concerned with one or more real-world entities, as we saw. It is to this issue that we now turn. ${ }^{15}$

\section{No [-atomic] for exclusive plurals}

Let us consider (1) and (2) again, repeated here:

(19) English

Lina harvested tomatoes

(20) English

Lina didn't harvest tomatoes

Inclusive plurals occur not only in contexts such as (20) or (21), but also in other downward-entailing contexts, such as (22) (restriction of no or few), (23) (if-clause) or (24) (restriction of a universal quantifier), and in questions, as in (25). Further examples of English exclusive plurals are provided in (26):

(21) English

a. I don't have children

b. Dogs are not barking outside

15 Rothstein (2010) argues that atomicity is context dependent, as can be seen from the fact that what counts as a single fence, twig, or line may vary. Harbour does not build context-dependent atomicity in his account, but this could be done via a head embedded in $\mathrm{nP}$, or via $\mathrm{n}$ itself, which introduces a function that is sensitive to Rothstein's counting context. 
(22) English

Few/no students came to the party

(23) English

[Directed at one person:] ${ }^{16}$

If you spot horses in this picture, you will get a prize

(24) English

Every house with windows overlooking the ocean is overpriced

(25) English

[Directed at one person:]

a. Have you ever seen horses in this meadow?

b. Did you eat apples today?

(Farkas and de Swart 2010)

(26) English
a. I have children
b. Dogs are barking outside

(Carlson 1977)

Inclusive plurals do not occur just in non-episodic, generic, or law-like sentences, such as (21)a, (24) or (25)a-they also occur in plain episodic sentences such as (20), (21)b, (22), (23), or (25)b. ${ }^{17}$

These facts have been taken to show that plural forms in English are, semantically, not exclusive but inclusive, as in Dvorak and Sauerland (2006), Krifka $(1989,1995)$, Ivlieva (2013), Lasersohn (1998, 2011), Sauerland (2003), Sauerland, Anderssen and Yatsushiro (2005), Spector (2007), Yatsushiro, Sauerland and Alexiadou (2017) or Zweig (2009). The basic structure of the explanation in inclusive-only accounts contains three ingredients: (a) an inclusive, number-neutral semantics for common count plural nouns and DPs (e.g., as in (27) for the noun cats), (b) a singular semantics for singular

\footnotetext{
16 With a singular addressee, we stay away from issues of dependent plurality (cf. Ivlieva 2013, Zweig 2009).

${ }^{17}$ In other languages, plurals in sentences of the form of (21)a, (24) or (25)a receive exclusive, not inclusive, interpretations:
}

(i) Turkish (Görgülü 2012)

Çocuk-lar-ın var mi?

child-PL-GEN exist Q

'Do you have two or more children?'

(ii) Western Armenian (Bale et al. 2011, Bale and Khanjian 2014)

$\begin{array}{ll}\text { Bozdig-ner } & \text { unis? } \\ \text { child-INDEF.PL } & \text { have.2SG.PRES }\end{array}$

'Do you have two or more children?'

(iii) Brazilian Portuguese (Martí 2008, Müller 2002)

$\begin{array}{lllll}0 & \text { João } & \text { não } & \text { tem } & \text { filhos } \\ \text { DEF } & \text { João } & \text { NEG } & \text { have.3SG.PRES } & \text { child.PL }\end{array}$

'João does not have (two or more) children'

The claims about the interpretation of plural forms in these languages are not uncontroversial though (see Renans et al. 2017 and Sağ 2017 for Turkish, for example). 
nouns and DPs (e.g., as in (28)), and (c) a post-compositional mechanism that derives exclusive plural meanings on the basis of $(a)$ and $(b)$ :

$$
\begin{aligned}
& {[[\text { cats }]]=\lambda x \cdot \operatorname{cat}(x)} \\
& {[[\text { cat }]]=\lambda x \cdot \operatorname{cat}(x) \& \operatorname{atom}(x)}
\end{aligned}
$$

In these accounts, nothing in the structure of plural DPs is responsible for exclusive plural interpretations. The details of the post-compositional mechanism vary by account, but, at its most basic, the mechanism relies on competition between (a) and (b). Consider a negative context such as (21)a. An inclusive-only system straightforwardly assigns the proposition that the speaker doesn't have any children to (21)a-and that is indeed the interpretation of the plural form in this example. Exclusive interpretations can be explained by appealing to pragmatic competition between (a) and (b). The proposition assigned to a sentence such as (26)a, an upwardentailing context, by an inclusive-only system is the proposition that the speaker has one or more children. This proposition is less informative than/entailed by the proposition that results from the use of the singular form, namely, that the speaker has exactly ${ }^{18}$ one child. Given Gricean competition, since the speaker didn't choose the more informative proposition, the hearer concludes that the weaker proposition is false (i.e., the speaker doesn't have one child and s/he has more than one)-that's the exclusive interpretation that we find in (20). ${ }^{19,20}$ The important ingredient of inclusive-only accounts for the argument that follows is that the only semantic option for plural forms is (a). Other details, such as the particular nature of (c), are independent of my argument.

In this section I consider, and argue against, two possible modifications to Harbour's system that are intended to solve the inclusive plurals problem. The two modifications involve dispensing with semantic plurality, that is, with [-atomic], to different degrees, so as to preserve the inclusive-only type of account. According to the first modification, discussed in section 3.1, languages with inclusive plurals are number systems that dispense entirely with [-atomic]. My argument against this solution is that it predicts that languages with inclusive plurals and [-atomic]-based number values such as dual or paucal should not exist, contrary to fact. According to the second modification, discussed in section 3.2, languages with inclusive plurals are number systems that dispense with [-atomic] only for inclusive plurals. My argument is that the cross-linguistic typology of number that Harbour's theory is designed to capture is no longer captured if the theory is modified in this way.

\subsection{No [-atomic] at all}

The first version of the inclusive-only approach to the inclusive plurals problem involves the following claim: languages with inclusive plurals do not make use of a

\footnotetext{
${ }^{18}$ As per Spector (2007).

19 This impressionistic explanation is not quite right. What Gricean competition delivers, as has often been pointed out (see Sauerland 2005 and others; also, Chierchia, Fox and Spector 2012), is the weaker proposition that the speaker doesn't believe that s/he has one child.

${ }^{20}$ Questions, as in (25), are not, strictly speaking, downward-entailing (though NPIs are licensed in questions; Ladusaw 1996, Guerzoni and Sharvit 2007) and are, implicitly or explicitly, put aside in all accounts of inclusive plurals (though see Grimm 2012).
} 
feature [-atomic] at all for count nouns. The basic idea is that the denotations of singular and plural forms in a language like English are as follows:

(29) a. $[[$ cat $]]=[[+$ atomic $]]([[\mathrm{nP}]])=\lambda \mathrm{x} . \mathrm{x}$ is a cat $\&$ atom $(\mathrm{x})$

b. $[[$ cats $]]=[[\mathrm{nP}]]=\lambda \mathrm{x}$. $\mathrm{x}$ is a cat

(singular)

(plural)

(29)a assigns an atomic semantics to singular DPs, and (29)b assigns a number-neutral semantics to plural DPs. There is no [-atomic] feature at all in this number system. This solution involves modifying Harbour's theory so that the features [+atomic] and [-atomic] do not necessarily go together in a given number system. More specifically, it involves the claim that the presence of [+atomic] in a number system does not entail the presence of [-atomic]. Languages not making use of [-atomic] would be those with inclusive plurals, like English. Languages making use of [-atomic] would be those that do not have them, their plurals being always exclusive instead (recall footnote 17). Krifka (1989, 1995), Ivlieva (2013), Lasersohn (1998, 2011), Sauerland (2003), Sauerland, Anderssen and Yatsushiro (2005), Spector (2007), Yatsushiro, Sauerland and Alexiadou (2017) and Zweig (2009) are implementable within Harbour's theory in this manner.

The logic of my argument against it is as follows. If systems that dispense with [-atomic] altogether are allowed in Harbour's theory, then a language that has inclusive plurals must be one such system. Harbour's theory of number then predicts that such a language should not make use of [-atomic] elsewhere in the system: that is, it should not distinguish number values that make use of [-atomic], such as dual or paucal. However, this prediction is wrong, since languages with [-atomic]-based number values and inclusive plurals exist. I argue that Ljubljana Slovenian and Biak are examples of such languages.

Let's consider Slovenian first. Dual inflection is present on verbs, adjectives, cardinal numerals, nouns and various kinds of pronouns in Ljubljana Slovenian (Derganc 2003, Herrity 2015, Marušič and Žaucer to appear, Toporišič 2000)(recall section 2). Initial examples of the dual are as follows:

(30) Ljubljana Slovenian

$\begin{array}{lll}\text { Midva } & \text { rada } & \text { planinariva. } \\ \text { We.NOM.MASC.DU } & \text { willing.MASC.DU } & \text { hike.1DU }\end{array}$

'The two of us like to hike'

(31) Ljubljana Slovenian

$\begin{array}{lcll}\text { Na betonski } & \text { pingpong mizi } & \text { sta } & \text { fanta } \\ \text { on concrete } & \text { ping-pong table } & \text { AUX.DU } & \text { boy.NOM.MASC.DU } \\ \text { igrala } & \text { pingpong } & \\ \text { play.PTC.MASC.DU } & \text { ping-pong } & \\ \text { '(The) two boys played ping-pong on the concrete ping-pong table' }\end{array}$

Example (30) shows a dual form of the $1^{\text {st }}$ person pronoun in subject position, with agreeing elements in the dual. (31) shows a dual noun also in subject position, with the 
auxiliary and the verb in agreement. As shown in (31), dual number is compatible with both definite or indefinite interpretations. ${ }^{21}$

Importantly, Ljubljana Slovenian has inclusive plurals. Given the amount of syncretism between dual and plural forms in the feminine and the neuter in this language (recall Table 1), the best nouns to use to show this are masculine nouns in either Accusative or Nominative case, since then the dual is clearly different from the plural there. With this in mind, consider (32) and (33). In (32), seeing just one horse in the meadow already wins you the prize, and question (33)A can be answered as in (33)B, which also indicates an inclusive plural interpretation (recall the parallel English examples above):

(32) Ljubljana Slovenian

\begin{tabular}{|c|c|c|c|}
\hline $\begin{array}{l}\text { Kdor prvi } \\
\text { who first } \\
\text { nagrado } \\
\text { prize }\end{array}$ & $\begin{array}{l}\text { zagleda } \\
\text { see }\end{array}$ & $\begin{array}{l}\text { konje } \\
\text { horse.ACC.MASC.PL }\end{array}$ & $\begin{array}{l}\text { na tem travniku, } \\
\text { on this meadow }\end{array}$ \\
\hline
\end{tabular}

(33) Ljubljana Slovenian

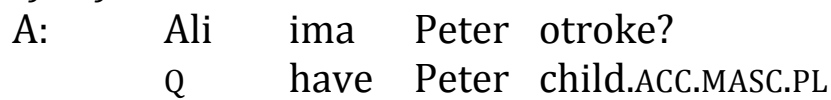

'Does Peter have children?'

B: Ja. Ima enega

Yes has one

'Yes, he has one'

In certain cases in even the masculine declension, the plural and dual forms are syncretic, so fantom in an example such as (34), while receiving an inclusive plural interpretation, is either the dual or the plural form:

(34) Ljubljana Slovenian

$\begin{array}{lllll}\text { Do danes fantom } & (\check{\text { še }} & \text { nisem } & \text { pomagal } \\ \text { until today boy.DAT.MASC.DU/PL } & \text { (yet) } & \text { NEG.AUX.1SG } & \text { help.PTC.SG } \\ \text { 'Until today I didn't help boys' } & & & \end{array}$

Making the noun unambiguously dual, however, as in (35), brings out an interpretation in which the dual is negated:

(35) Ljubljana Slovenian

$\begin{array}{llll}\text { Do danes fantoma } & \text { nisem } & \text { pomagal } \\ \text { until today boy.DAT.MASC.DU } & \text { NEG.AUX.1SG } & \text { help.PTC.SG } \\ \text { 'Until today I didn't help (the) two boys' } & \end{array}$

\footnotetext{
${ }^{21}$ More support seems needed from the context in order to fully license the indefinite interpretation in this case, e.g., an enumeration context in which the speaker is describing the people who were in the park earlier and what they were doing. Dvorak and Sauerland (2006) and Marušič and Žaucer (to appear) discuss this issue further, with Dvorak and Sauerland proposing that the dual is presuppositional-a statement that is too strong, given the availability of indefinite, non-presuppositional interpretations in this and other examples in this paper. With personal pronouns, as in (30), only definite interpretations are possible, personal pronouns themselves being definite.
} 
Since such a negated dual interpretation is absent in (34), the claim that (34) involves the use of an inclusive plural seems correct, with (negated) dual interpretations arising only when the form is unambiguously dual, as in (35). In the Nominative case, nouns in the feminine declension also show syncretism, but it is possible to disambiguate by combining them with agreeing verbs, as in (36) (recall footnote 6):22

(36) Ljubljana Slovenian

$\begin{array}{lll}\text { Rože } & \text { ne } & \text { cvetijo } \\ \text { flower.NOM.FEM.PL } & \text { NEG } & \text { blossom.3PL }\end{array}$

'(The) flowers aren't blossoming'

The form rože may be either dual or plural, but in (36), the agreeing verb indicates that it is the plural version that is chosen. (36) receives an inclusive plural interpretation. Consider also (37) and (38):

(37) Ljubljana Slovenian

Nimam otrok.

NEG.have.1SG child.GEN.MASC.DU/PL

'I don't have children'

(38) Ljubljana Slovenian

$\mathrm{Ne} \quad$ vidim konjev na travniku.

NEG see horse.GEN.MASC.DU/PLon meadow

'I didn't see horses in the meadow'

Even verbs that normally take Accusative objects must take Genitive ones in the context of negation in (Ljubljana) Slovenian, a phenomenon, well-known in the context of Slavic languages, known as Genitive of Negation. Since the dual and the plural are always syncretic in Genitive case (recall Table 1), it is not possible to tell which of the dual or plural form is being used in (37) and (38). As before, however, (37) and (38) are interpreted inclusively and are not ambiguous between an inclusive plural reading and a negated dual reading. For the latter, unambiguously dual forms are needed, as in (39) and (40), where the numeral dveh 'two' requires dual:

(39) Ljubljana Slovenian

$\begin{array}{lll}\text { Nimam } & \text { dveh } & \text { otrok. } \\ \text { NEG.have.1sG } & \text { two.GEN.MASC.DU } & \text { child.GEN.MASC.DU }\end{array}$

'I don't have two children'

(40) Ljubljana Slovenian

$\mathrm{Ne}$ vidim dveh konjev na travniku.

NEG see two.GEN.MASC.DU horse.GEN.MASC.DU on meadow

'I didn't see (the) two horses in the meadow'

Inclusive plural interpretations also arise in the restriction of universal quantifiers, another downward-entailing context, as shown in (41):

22 Thanks to Christina Sevdali for asking about this example. 
(41) Ljubljana Slovenian

Vsaka hiša $\quad \mathrm{ki}$ ima okna
every house.NOM.FEM.SG which has window.ACC.NEUT.DU/PL with

Example (34), with the plural form in a negative environment, contrasts with an example like (42), where the plural form is in an upward-entailing environment and is interpreted exclusively (the number of students that got run over is three or more):

\section{(42) Ljubljana Slovenian}

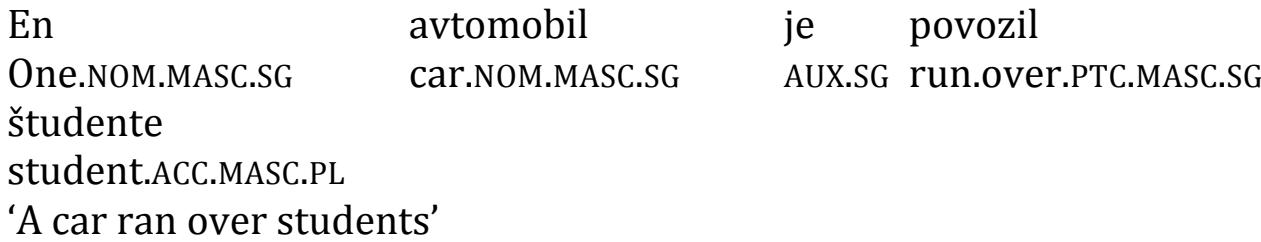

Example (41) contrasts with (43), where the plural form okna 'windows' is no longer in a downward-entailing environment and is interpreted exclusively (we are now considering a house with three or more windows): ${ }^{23}$

(43) Ljubljana Slovenian

$\begin{array}{lll}\text { Ena } & \text { hiša } & \text { ki ima okna } \\ \text { one NOM.FEM.SG house.NOM.FEM.SG which has window.ACC.NEUT.DU/PL with } \\ \text { pogledom } & \text { na morje je precenjena } \\ \text { view } & \text { on sea } \quad \text { is overpriced } \\ \text { 'One house which has windows with a view of the sea is overpriced' }\end{array}$

A proposal to deal with the inclusive plurals of Ljubljana Slovenian that does not use [-atomic] at all for this language predicts that its number system should not have a dual number value, since [-atomic] wouldn't be available to derive the dual. However, Ljubljana Slovenian is a singular-dual-plural system on nouns. In other words, if Harbour's theory is modified so as to allow languages with inclusive plurals to be [-atomic]-less systems, then the resulting theory predicts that languages with inclusive plurals should have no dual (or any other number value based on [-atomic]), contrary to fact.

It is possible to make the same argument with languages that have other number values based on [-atomic], such as Biak, the Indonesian language discussed in section 2, with the caveat that the locus of the expression of number features is not on nouns in this language: in addition to demonstratives and determiners, Biak uses subject agreement verbal prefixes to express number distinctions. Examples (44) and (45) illustrate agreement with singular and plural bare subjects:

\footnotetext{
${ }^{23}$ In (42) and (43), some speakers report that an inclusive interpretation is possible if the example is interpreted "in a sort of generic way". This is not at all unexpected in languages with inclusive plurals; something similar happens in English. For more on this, see footnote 27.
} 
(44) Biak

Ikak (oso) d-arek i

snake one 3SG-bite PRON.3SG

'A snake bit him'

(45) Biak

Ikak s-arek i

snake 3PL.ANIM-bite PRON.3SG

'Snakes bit him' (at least four snakes)

Bare dual and paucal nouns cannot serve as subjects for independent reasons in Biak (see Dalrymple and Mofu 2013: 49-50), but non-bare ones show the corresponding verbal agreement, as shown in (46) and (47):

(46) Biak

Ikak $\quad$ (suya) su-arek i

snake DEF.3DU 3DU-bite PRON.3SG

'The two snakes bit him'

(47) Biak

Ikak $\quad *$ (skoya) sko-arek i

snake DEF.3PAUC 3PAUC-bite PRON.3SG

'The three/several snakes bit him'

In Harbour's terms, as we saw, Biak is [ \pm additive, \pm minimal, \pm atomic], with duals and paucals, that is, with number values built with [-atomic]. Yet, Biak has inclusive plurals, as argued for in Dalrymple and Mofu (2013):

(48) Biak

Ikak (ono) s-arek i ba

snake INDEF 3PL.ANIM-bite PRON.3SG NEG

'Snakes did not bite him/no snakes bit him'

(49) Biak

Ikak (ono) s-arek i ke?

snake INDEF 3PL.ANIM-bite PRON.3SG Q

'Did snakes bite him?'

Example (48), with sentential negation, is interpreted inclusively, and so is (49). A positive answer to (49) informs that one or more snakes bit him; with a negative one, that no snakes did. Again, a solution to the inclusive plurals problem that assumes just an inclusive semantics for plural DPs, coupled with Harbour's decompositional account of duals and paucals, predicts that Biak should not have inclusive plurals, contrary to fact. 


\section{2 [-Atomic] sometimes ${ }^{24}$}

A second version of the inclusive-only approach to inclusive plurals involves the following claim: languages with inclusive plurals do not use [-atomic] for plural DPs, but may use [-atomic] elsewhere, e.g., for dual DPs. Consider a language with a singulardual-plural number system and inclusive plurals, such as Ljubljana Slovenian. According to this version, we would have:

(50) a. $[[$ stol $]]=[[+$ minimal $]]([[+$ atomic $]]([[\mathrm{nP}]]))$

(singular)

$=\lambda \mathrm{x} . \mathrm{x}$ is a chair \& atom $(\mathrm{x}) \& \neg \exists \mathrm{y}$ atom $(\mathrm{y}) \& \mathrm{y} \sqsubset \mathrm{x}$

b. $[[$ stola $]]=[[+$ minimal $]]([[-$ atomic $]]([[$ nP $]]))=$

$=\lambda \mathrm{x} . \mathrm{x}$ is a chair $\&$ atom $(\mathrm{x}) \& \neg \exists \mathrm{y}$ ᄀatom $(\mathrm{y}) \& \mathrm{y} \subset \mathrm{x}$

c. $[[$ stoli $]]=[[\mathrm{nP}]]=\lambda \mathrm{x}$. $\mathrm{x}$ is a chair

(plural)

The basic idea is that duals (or paucals) are not built of the same building blocks as plural forms. Because the denotation of plural forms needs to be inclusive, [-minimal] is not used in (50)c, and thus perhaps not at all for Ljubljana Slovenian. ${ }^{25}$ Theories such as Dvorak and Sauerland (2006), Krifka $(1989,1995)$, Ivlieva (2013), Lasersohn (1998, 2011), Sauerland (2003), Sauerland, Anderssen and Yatsushiro (2005), Spector (2007), Yatsushiro, Sauerland and Alexiadou (2017) or Zweig (2009) are implementable within Harbour's theory in this manner.

This version of the inclusive-only approach is also problematic. The explanatory power of Harbour's theory relies on certain number values being generated using the same feature. But in (50), whereas dual forms would use [-atomic], plural forms wouldn't. As Nevins (2011) has argued, the formal link between duals and plurals, pioneered by Noyer (1992) and adopted by Harbour $(2011,2014)$, is crucial in the account of the cross-linguistic typology of number. For example, because both duals and plurals make use of the feature [-atomic], the prediction is that no language should exist with dual but no plural-this is the correct prediction, as we know (see section 2). Related to this is that dual is lost before plural in the course of language change, never the other way around, a fact that a decompositional account of the dual is designed to explain. Consider the decompositional analysis of singular-dual-plural systems in (16), repeated in (51), where there are three possible paths of loss: either the feature [ \pm minimal] is lost, the feature [ \pm atomic] is lost, or both features are lost. If both features are lost at the same time, the language would become a language with no grammatical number. More interesting is the loss of the feature [ \pm minimal], which results in the singular-plural system in (52), with (52)b and (52)c now equivalent (on the assumption that, since the dual meaning is lost with the loss of [+minimal], the form that used to spell out that meaning is lost):

(51) a. $[[+$ minimal $]]([[+$ atomic $]]([[\mathrm{nP}]]))=$

$=\lambda x \cdot[[n P]](x) \&$ atom $(x) \& \neg \exists y$ atom $(y) \& y \sqsubset x$

b. $[[+$ minimal $]]([[-$ atomic $]]([[\mathrm{nP}]]))=$

$=\lambda \mathrm{x} .[[\mathrm{nP}]](\mathrm{x}) \&$ atom $(\mathrm{x}) \& \neg \exists \mathrm{y}\urcorner \operatorname{atom}(\mathrm{y}) \& \mathrm{y} \sqsubset \mathrm{x}$

(singular)

\footnotetext{
${ }^{24}$ Thanks to an anonymous reviewer for suggesting this possibility.

${ }^{25}$ It is likely that the complete omission of [-minimal] from such a system will create problems not too dissimilar from the under-generation problem of the first version, discussed in section 3.1, but I leave the exploration of the consequences of positing [-minimal]-less systems for another time.
} 
c. $[[-$ minimal $]]([[-$ atomic $]]([[\mathrm{nP}]]))=$

(plural)

$=\lambda \mathrm{x} .[[\mathrm{nP}]](\mathrm{x}) \&$ atom $(\mathrm{x}) \& \exists \mathrm{y} \neg$ atom $(\mathrm{y}) \& \mathrm{y} \subset \mathrm{x}$

(52) a. $[[+$ minimal $]([[+$ atomic $]]([[\mathrm{nP}]]))=$

(singular)

$=\lambda \mathrm{x} .[[\mathrm{nP}]](\mathrm{x}) \& \operatorname{atom}(\mathrm{x})$

b. $[[+$ minimal $]([[-$ atomic $]]([[\mathrm{nP}]]))=$

(dual)

$=\lambda \mathrm{x} \cdot[[\mathrm{nP}]](\mathrm{x}) \&$ atom $(\mathrm{x})=$

c. $[[-$ minimal $]([[-$ atomic $]]([[\mathrm{nP}]]))=$

$=\lambda \mathrm{x} .[[\mathrm{nP}]](\mathrm{x}) \&$ atom $(\mathrm{x})$

(plural)

The loss of [ \pm atomic] results in a [ \pm minimal] system, possibly also a singular-plural system, with (53)a and (53)b now equivalent:

(53) a. $[[+$ minimal $]]([[+$ atomic $]\}([[\mathrm{nP}]]))=$

$=\lambda x \cdot[[\mathrm{nP}]](\mathrm{x}) \& \neg \exists \mathrm{y}[[\mathrm{nP}]](\mathrm{y}) \& \mathrm{y} \subset \mathrm{x}=$

b. $[[+$ minimal $]]([[-a t o m i c]]([[\mathrm{nP}]]))=$

(singular)

$=\lambda x \cdot[[\mathrm{nP}]](\mathrm{x}) \& \neg \exists \mathrm{y}[[\mathrm{nP}]](\mathrm{y}) \& \mathrm{y} \subset \mathrm{x}$

(dual)

c. $[[-$ minimal] $]([[-$ atomic $]\}([[\mathrm{nP}]]))=$

$=\lambda x \cdot[[n P]](x) \& \exists y[[n P]](y) \& y \sqsubset x$

(plural)

In other words, in Harbour's system, it is not possible to lose [-atomic] in the plural without also losing it in the dual, and losing [-atomic] in the dual entails losing the dual (likewise, it is not possible to lose [+minimal] in the singular without also losing it in the dual, and losing [+minimal] in the dual entails losing the dual). That dual is acquired by children after plural also follows from the decompositional account of the dual, as Nevins (2011) explains in more detail. According to the second version of the inclusiveonly approach, however, losing (50)c does not entail losing (50)b, since they have no features in common. This means that according to this version, languages with dual but no plural are possible-an over-generation problem again. The approach also predicts that the plural can be lost before the dual in the course of language change, and that the dual can be acquired before the plural. Problems of this very nature will arise in any system with inclusive plurals and any other number values based on [-atomic], such as paucals, exemplified above for Biak and Bayso. ${ }^{26}$

${ }^{26}$ Dvorak and Sauerland (2006), following Sauerland (2003), posit three number features for Slovenian, [SINGULAR], [DUAL], and [PLURAL]. Their semantic effect is just as in (50), with three differences: (a) the content of [SINGULAR] and [DUAL] is stipulated, not compositionally derived (their end effect is as in (50)a and $(50) \mathrm{b}$, respectively, but this is not achieved by using the features [+minimal] and [ \pm atomic]), (b) the singularity and duality import of [SINGULAR] and [DUAL] is presuppositional, not in terms of entailments, and (c) the head that contains such features is generated above DP, not DP-internally, so its semantic type is different. Difference (b) determines the pragmatic principle that Dvorak and Sauerland invoke to generate exclusive plural interpretations, Heim's Maximize Presupposition, as in Sauerland (2003) and others, a principle which is very close to the pragmatic competition account described in section 3.1. [PLURAL] in Dvorak and Sauerland denotes just an identity function, without presuppositions. This proposal predicts that languages with duals and inclusive plurals are indeed possible, so the undergeneration problem discussed in section 3.1 does not arise. This is the case for any approach that pursues the second version: since, by definition, [-atomic] (or [-minimal]) is not used for plural forms, inclusive plural forms are entirely possible. Crucially, however, assumption (a) stipulates the semantics of the dual as a primitive, and that does create a significant, over-generation problem: if [DUAL] is a primitive feature, what prevents [TRIAL], [PAUCAL], [GREATER PLURAL], [MINIMAL], etc. from being primitives as well? Nothing prevents any logically possible, but unattested, number system from being generated, e.g., one with the features [SINGULAR] and [TRIAL], but no [DUAL] or [PLURAL]. 


\section{4 [-Atomic] or exhaustive exclusive plurals}

\subsection{Ambiguity accounts}

The basic structure of an ambiguity account of inclusive plurals contains three ingredients: (a) an inclusive, number-neutral semantics for common count plural forms, (b) an additional, exclusive, strictly plural semantics for the same forms, and (c) a postcompositional mechanism that chooses between (a) and (b). In Farkas and de Swart (2010), (c) is the Strongest Meaning Hypothesis (from Dalrymple et al. 1998):

(54) The Strongest Meaning Hypothesis: when an expression is assigned a set of interpretations ordered by entailment, choose the strongest element of this set that is compatible with the context

(a) and (b) in this account give rise to interpretations that are in an asymmetric entailment relation. For example, with a sentence such as (19), repeated here as (55), if it is true that Lina harvested two or more tomatoes (exclusive interpretation), then it is necessarily true that Lina harvested one or more tomatoes (inclusive interpretation):

(55) English

Lina harvested tomatoes

If Lina harvested one or more tomatoes (inclusive interpretation), however, it doesn't necessarily follow that Lina harvested two or more tomatoes (exclusive interpretation)-she could have harvested an atomic individual tomato. In these circumstances, and everything else being equal, the Strongest Meaning Hypothesis applies and chooses the strongest, exclusive interpretation. In downward-entailing environments, such the negative sentence in (20), repeated as (56), antecedents of conditionals, or restrictions of universal quantifiers, entailment relations are reversed:

(56) English

Lina didn't harvest tomatoes

In (56), the proposition that Lina harvested neither one nor more tomatoes (inclusive interpretation) asymmetrically entails and is thus stronger than the proposition that Lina didn't harvest two or more tomatoes (exclusive interpretation). Thus, the result is that, everything else being equal, inclusive plurals occur in downward-entailing environments (and in questions; recall footnote 19), and exclusive plurals occur in upward-entailing environments, as desired. From the perspective of the argumentation in this paper, the important difference between the inclusive-only accounts of section 3 and the ambiguity account just presented is that, semantically, the ambiguity account postulates not one but two lexical entries for plural count nouns. The mechanisms assumed in the former to derive exclusive interpretations and in the latter to choose between competing interpretations are not the same, but the differences here are independent of my argument. 27

${ }^{27}$ As shown by Farkas and de Swart, the Strongest Meaning Hypothesis predicts that there are contexts in which the entailing proposition might not be chosen-as long as the entailed proposition is the strongest in that particular context. This is confirmed in examples such as (i), where children is in upward-entailing environment but interpreted inclusively, or the Ljubljana Slovenian example in (ii): 
In the featural account of Harbour (2014), the implementation of the ambiguity account is not concerned with lexical entries but with the denotation, and presence, I suggest, of NumP. From this perspective, the idea is that plural count noun forms have two options with respect to NumP. The first option, for exclusive interpretations, involves for, e.g., English, the feature [-atomic] in $\mathrm{Num}^{0}$ (recall (13)):

(57)

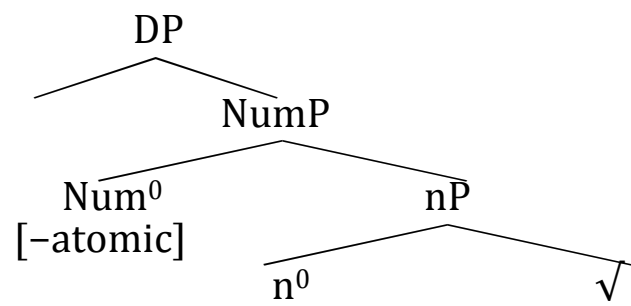

The second option, for inclusive interpretations, involves, for the same language, DPs with no NumP:

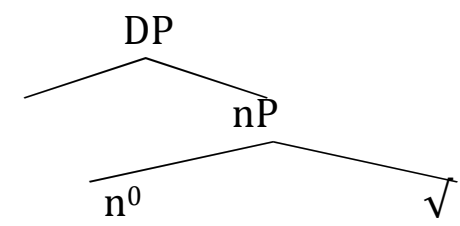

Without NumP, the interpretation of the plural form contains both atoms and nonatoms and is, thus, inclusive. The Strongest Meaning Hypothesis, or whatever else one postulates for (c), will do the rest. In this account, plural forms in a language with inclusive plurals happen to spell out two different structures, (57) or (58).

The proposal just sketched does not run into the problems pointed out earlier for inclusive-only approaches. Languages with [-atomic]-based number values, such as dual (Ljubljana Slovenian) or paucal (Biak), and inclusive plurals are indeed predicted to be possible languages. Their account is just as in Harbour (see section 2), with three

(i) English

[Speaker walks into unknown house, notices toys littering the floor, has no way of telling how many children there are in the house]:

There are children in this house

(ii) Ljubljana Slovenian

[Speaker walks into unknown house, notices toys littering the floor, has no way of telling how many children there are in the house]:

$\begin{array}{llllll}\text { Poglej } & \text { vse te } & \text { igrače }-\mathrm{v} & \text { hiši } & \text { so } & \text { otroci. } \\ \text { look } & \text { all DEM.PL } & \text { toy.PL in } & \text { house.DAT.FEM.SG } & \text { AUX.PL } & \text { child.NOM.MASC.PL }\end{array}$

'Look at all these toys - there are children in the house'

The strongest meaning compatible with the knowledge state of the speaker is the inclusive meaning. Without information about the knowledge of the speaker, it is likely that speakers will make default assumptions, such as, for example, that the speaker is knowledgeable. Cases of downward-entailing environments with exclusive interpretations also exist (Chierchia, Fox and Spector 2012: 2318):

(iii) John may have read one book, but I don't think he has read books

Other accounts discussed here can also handle these examples. Biak examples such as (45) should be able to receive an inclusive interpretation in the right context, e.g., if the number of snakes that bit the relevant person is irrelevant, a prediction which remains to be verified. 
crucial additions: plural forms in these languages can also spell out (58), languages have mechanisms that allow them to choose between (57) and (58) (e.g., the Strongest Meaning Hypothesis), and languages without inclusive plurals do not make use of (58). There are also no over-generation problems of the kind discussed in section 3.2. Because plural forms and dual and paucal forms share the feature [-atomic], as in Harbour, the paths of acquisition and loss that Harbour explains can still be explained now. For example, languages with duals but no plurals are still predicted not to be possible, since they both use [-atomic]. ${ }^{28}$

There are at least two important questions to answer at this point. The first is whether it is sensible to postulate (58) in Harbour's system. The second question is whether other ambiguity-based approaches would also work. The remainder of this section answers these questions.

(58) is in fact one possibility considered in Harbour (2014) for languages that make no grammatical number distinctions at all, such as Pirahã or Dëne Sųłiné. ${ }^{29}$ The more interesting question is whether there is independent evidence that (58) is a possibility even in languages that do make grammatical distinctions. I argue that (58) is in fact a very plausible analysis for general number, a number value attested in languages such as the Fouta Jalon dialect of Fula (a Niger-Congo language spoken in Guinea), as well as Bayso, discussed above, which can co-exist with other grammatical number distinctions (Corbett 2000, 2012).

Both Bayso and Fouta Jalon Fula make a singular-plural distinction, with Bayso having, in addition, a paucal number value, as we saw in section 2 . In both languages, singular and plural (and paucal) are expressed via dedicated suffixes. They also have general number, expressed via bare stems. General number has the semantic import of number neutrality, as evidenced for Bayso in (59)a (Corbett 2000, 2012, Corbett and Hayward 1987, Hayward 1979) (recall (3))(for Fouta Jalon Fula, see Corbett 2000:12 and Koval' 1979):30

\begin{tabular}{|l|l|l|l|}
\hline & GENERAL & SINGULAR & PLURAL \\
\hline toad & toti & totii-ru & totii-ji \\
\hline cat & nyaari & nyaarii-ru & nyaarii-ji \\
\hline hen & gerto & gerto-gal & gertoo-de \\
\hline egg & boofo & woofoo-nde & boofoo-de \\
\hline bottle & biini & biinii-ri & biinii-ji \\
\hline
\end{tabular}

Table 4 Nouns in the Fouta Jalon dialect of Fula

(59) Bayso
a. Lúban
hudure
lion.GENERAL sleep.MASC.SG.PAST
'Lions/A lion slept'

\footnotetext{
${ }^{28}$ Harbour (2016: 149-152) briefly entertains a solution to the inclusive plurals problem that makes use of a function which, operating on the set of non-atoms provided by NumP, accesses the atoms that constitute them. This is another possible version of the ambiguity account. This version does not allow inclusive plurals to be subsumed under general number, since there would be no justification for using this procedure in the case of languages without grammatical number, such as Pirahã or Dëne Sųłiné.

${ }^{29}$ One can alternatively assume for these languages that NumP is generated as part of DPs, but these languages have no number features to generate in Num. It doesn't seem like this choice has consequences for the argumentation in this paper, and I leave it unexplored here.

${ }^{30}$ I haven't been able to find Koval' (1979).
} 


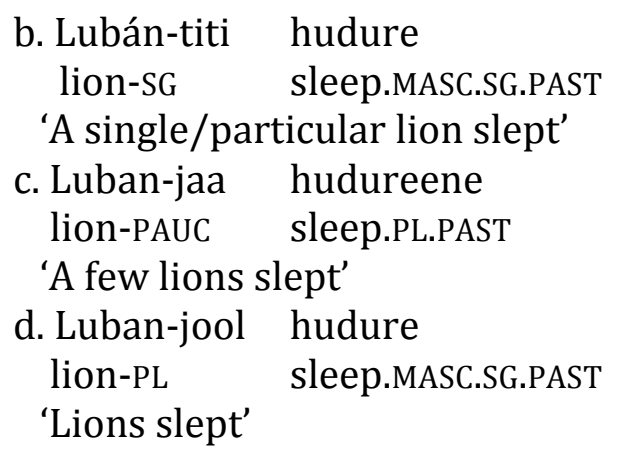

In Bayso, as Corbett (2012) shows, nouns in their general number form trigger patterns of verbal agreement that distinguish them from paucal and plural nouns. All paucalmarked nouns agree with the verb in the plural. Nouns that belong to the class of lúban 'lion' agree in masculine singular ${ }^{31}$ when in the singular, general number and plural forms, as can be seen from (59)a, (59)b and (59)d. General number and singular are then distinguished by the morphology on the noun and their respective semantics, as can be seen in the contrast between (59)a and (59)b. Nouns that belong to a separate class that includes kimbír 'bird' agree with the verb in the feminine singular when in the singular and the general number form and in masculine singular when in the plural form. A third class that includes baal 'feather/leaf' agrees in masculine singular when in the singular and the general form, but in plural when in the plural form, and so on. Thus, a number category beyond singular-paucal-plural is necessary in Bayso.

Even though general number in Bayso or Fouta Jalon Fula is not discussed explicitly by Harbour, the analysis for them in his system is clear: both languages allow NumP to be absent, though they don't force it to be so. When NumP is not generated as part of the structure of DP, nouns are interpreted as number-neutral or inclusive. Morphologically, the absence of NumP in these languages is realized as absence of number morphology. Semantically, general number forms are number-neutral, in the sense that the set denoted by $\mathrm{nP}$, not further operated on by $\mathrm{Num}^{0}$, contains both atomic and non-atomic individuals (recall (7) and (8)). Thus, a language like Bayso can naturally be thought of in Harbour's system as a [ \pm additive, \pm atomic] system with optional NumP. If this correct, then more languages than appear at first sight make use of the treatment of NumP that we find in Bayso or Fouta Jalon Fula, with one difference: languages may make use of an already existing form to spell out (58). In particular, languages may use their plural forms to do so. English, Ljubljana Slovenian and Biak would be examples of such languages. ${ }^{32,33}$

\footnotetext{
31 The basic agreement patterns in Bayso are determined on the basis of $3^{\text {rd }}$ person pronoun subject agreement. There is a three-way distinction here, with úsu the masculine singular form (with corresponding verbal agreement as in, e.g., hudure 'sleep.PAST.MASC.SG'; cf. (59)), ése the feminine singular form (verbal agreement as in hudurte 'sleep.PAST.FEM.SG'), and íso the plural form (verbal agreement as in hudureene 'sleep.PAST.PL') (Corbett 2012: 226, Corbett and Hayward 1987: 12).

32 The question arises, as Gabi Danon points out (p.c.), as to how subject-verb agreement works with general number if English has general number. One answer is that plural agreement is the elsewhere case: singular subjects agree in singular, and every other subject (plural, general number), in plural.

${ }^{33}$ Another question is whether forms other than plural forms may also spell out (58)/be inclusive. Pereltsvaig (2014) and Martí (2017) argue that inclusive plurals and inclusive singulars are two sides of the same phenomenon. The proposal defended here predicts that there should be languages which choose a form different from the plural to spell out NumP-less DPs. Sağ $(2016,2017)$ and Martí $(2017)$ argue that, despite appearances, Turkish bare singulars are not a case in point (cf. Corbett 2000). Brazilian Portuguese might be such a language, at least if Ferreira (2010) is right, but this possibility needs to be further evaluated within the context of the rich literature that exists on the topic of Brazilian
} 
Notice that combining this proposal for general number with the Strongest Meaning Hypothesis does not produce ill results for languages like Bayso. ${ }^{34}$ In particular, because the Strongest Meaning Hypothesis is formulated with respect to a given expression ("when an expression is assigned a set of interpretations ordered by entailment...", my emphasis), this principle has nothing to say about the choice of general number forms vs. other forms when these forms are different. In other words, general number forms such as lúban are never in competition with singular (lubántiti), paucal (lubanjaa) or plural forms (lubanjool) according to the Strongest Meaning Hypothesis. This is as it should be, at least from what we know about Bayso, since in upward-entailing contexts such as (59)a, general number forms give rise to inclusive, not exclusive, meanings. ${ }^{35,} 36,37,38$

Other versions of the ambiguity approach that avoid the problems of inclusiveonly approaches are possible, but they are not without other problems.

Grimm (2012) defends an alternative ambiguity-based approach to the problem of inclusive plurals. He proposes that plural forms in English are lexically ambiguous between an exclusive and an inclusive interpretation. The inclusive interpretation, however, is not simply stipulated-it is derived from kind interpretations. Starting with the kind DOG, for example, the set of instantiations of the kind is derived as the denotation of the plural form dogs (cf. Carlson 1977, Krifka 1995, Chierchia 1998b). This leads to a number-neutral, inclusive interpretation, since both atomic and nonatomic dog individuals count as instantiations of the kind DOG. The distribution of exclusive and inclusive interpretations is, he argues, sensitive to the episodic-generic

Portuguese bare noun semantics, to which I cannot to justice here (see, among others, Cyrino and Espinal 2015, Müller 2002, Pires de Oliveira and Rothstein 2011, Schmidt and Munn 2005). Whether yet other forms, such as duals or paucals, may also be inclusive remains to be explored.

34 Thanks to an anonymous reviewer for raising this issue.

35 The proposal predicts that plural DPs in Bayso are not ambiguous, and hence never give rise to inclusive plural interpretations. This prediction remains to be verified.

36 The proposal is compatible with there being other reasons that force a choice between the inclusive and the exclusive interpretation, e.g., if there are grammatical principles that are sensitive to the presence of atoms. Pereltsvaig (2014) argues that Russian inclusive plurals (general number plurals in the analysis in the text) are syntactically selected in a number of grammatical constructions.

37 On the other hand, this could prove problematic for the pragmatic mechanisms that are postulated as part of inclusive-only approaches (see section 3), since at least some of them allow competition of meanings that arise from different expressions (such as singular vs. semantically inclusive plural). I leave the development of this argument for future research.

38 Corbett (2000: 12) observes that in languages that have general number forms, these are used "when number is irrelevant". That contexts of number irrelevance favor the use of general number forms suggests that, besides speaker ignorance (cf. footnote 27), number irrelevance should also play a role in the account of inclusive plurals if indeed these are general number forms. This seems to be the case:

\section{(i) English}

[The speaker works for the town hall and is going around the neighbourhood distributing leaflets about childcare options. She is fully informed of the number of children residing in 82a and 82c Bethune Road; in fact, she is looking at the list with information extracted from the census and knows that one child resides in $82 \mathrm{a}$, and three children reside in $82 \mathrm{c}]$ :

There are children in $82 \mathrm{a}$. There are children in $82 \mathrm{c}$. But there are no children in $82 \mathrm{~b}$

The plural form children is interpreted inclusively in the first sentence of (i), or else the fact that only one child resides in $82 \mathrm{a}$ should make the first sentence false. The speaker is fully informed of the exact number of children residing in each house, but what is important in the context is not the exact number of children, but whether there are any children at all residing at a particular address. As long as the number of children residing at an address is at least one, childcare leaflets are called for at that address. 
distinction: inclusive, kind-based interpretations occur in kind/generic environments, and exclusive interpretations occur in episodic environments.

Because this approach does postulate the existence of (what in Harbour's system would be) [-atomic] exclusive plurals, it does not suffer from the under- or overgeneration problems of inclusive-only approaches and is thus consistent with the thesis defended in this paper. One important problem from our perspective, however, is that kind interpretations cannot be the (only) source of inclusive plurals. In English, bare plurals like parts of this machine or pieces of that puzzle never denote kinds, and as such cannot be the subject of a kind predicate, as shown in (60) (Carlson 1977), yet inclusive interpretations are possible for them (Chierchia 1998b: 373, van Geenhoven 2000: 234), as shown in (61):

(60) English

?? Parts of this machine are widespread

(61) English

John didn't see parts of this machine

Whether (61) allows wide scope ("there are parts of this machine such that John didn't see them") in addition to narrow scope ("it is not the case that John saw any parts of this machine") is debatable (see van Geenhoven 2000), but it is clear that (61) has a narrow scope interpretation, and that that interpretation is an inclusive interpretation. Furthermore, a kind analysis is not an option for languages where nouns cannot denote kinds by themselves, such as Spanish, Italian, Hungarian, or Arabic, even though these languages allow bare nouns in argument position (to different degrees) (see Doron 2003, Dobrovie-Sorin, Bleam and Espinal 2006 and references cited there). Yet, these languages may have inclusive plurals. Consider, for example, Spanish (Laca 1996: 262, McNally 2004: 118):

(62) Spanish

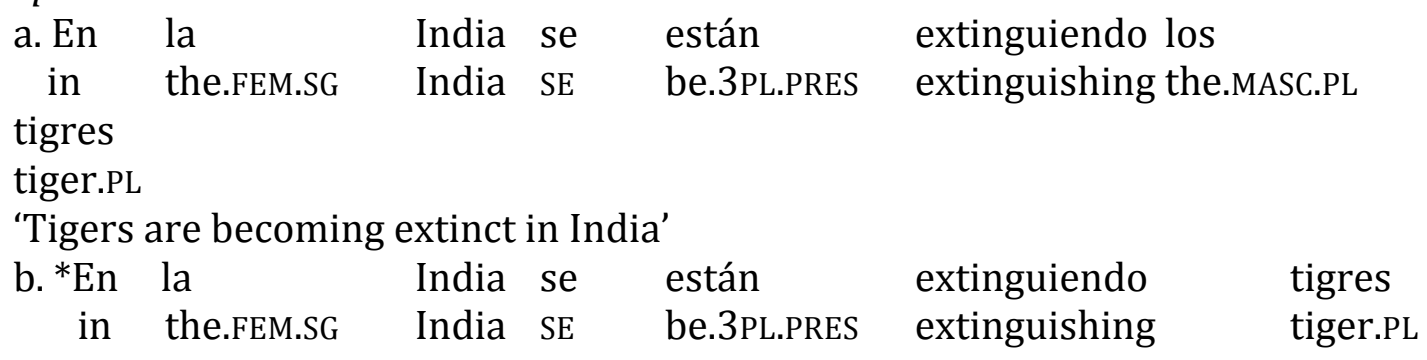

The subject of the predicate extinguirse 'to become extinct' is kind-denoting, and (62)b is ungrammatical (note that bare plural subjects are normally allowed in postverbal position in Spanish, as in (63) and (64) below). (62)a, where the plural form is accompanied by the definite article, is, on the other hand, grammatical. Thus, plural forms in Spanish by themselves cannot produce a kind denotation. Yet, Spanish has bare inclusive plurals, as in (63) (cf. (64))(Laca 1996: 262, Martí 2008, McNally 2004: 118):

(63) Spanish

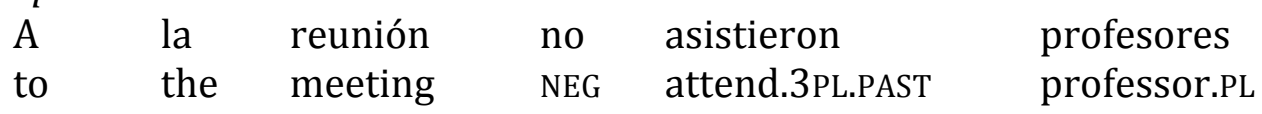

'The meeting was not attended by any professors' 
(64) Spanish

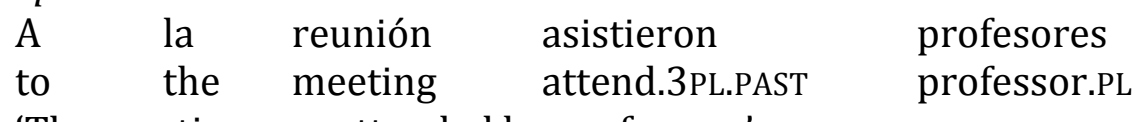

'The meeting was attended by professors'

A further alternative ambiguity-based approach claims that the source of inclusive plural interpretations is not kinds but noun incorporation (see Baker 1988 and Mithun 1984, 1986, among others, for early analyses of incorporation). This version of the ambiguity account would maintain (what in Harbour are) [-atomic] exclusive plurals, like Grimm (2012), but would claim that the source of the number-neutral, inclusive interpretation of inclusive plurals is incorporation. Incorporated nominals tend to be interpreted number neutrally (Carlson 2006 and Dayal 2015). van Geenhoven (1998) hypothesized that, parallel to morpho-syntactic incorporation, there is a corresponding rule of interpretation where a verb may introduce existential quantification over its (property-denoting) object. Since van Geenhoven assumes that nouns contain both atoms and non-atoms in their denotation, number neutrality results. Indeed, van Geenhoven (2000) and McNally (2004) extend the use of semantic incorporation to bare plurals in English and Spanish, respectively, explicitly hypothesizing that application of the rule of semantic incorporation need not be accompanied by the morpho-syntactic rule. A semantic incorporation analysis of inclusive plurals would say that plural forms undergo semantic incorporation in downward-entailing contexts (and questions); singular forms would not be subject to this rule at all (given, e.g., *I have child). Because this ambiguity-based account would keep [-atomic] exclusive plurals, no under- or over-generation problems arise, as before. The main problem with this proposal is different, and it is that it does not constitute a real solution to the problem of inclusive plurals. This is because the rule of semantic incorporation does not per se introduce number neutrality-its semantic import follows from assumptions about the semantics of the nouns that undergo the rule. In fact, in languages where plural forms undergo morpho-syntactic (pseudo-)incorporation, such as Hungarian (Farkas and de Swart 2003), these forms are interpreted exclusively, not inclusively. ${ }^{39,40,41}$

\subsection{Replacing [-atomic] with an exhaustivity operator ${ }^{42}$}

The basic structure of this type of account, developed by Mayr (2015), has the following ingredients: (a) an inclusive semantics for plural forms, (b) a predicate-level, individual-sensitive, DP-internal exhaustivity operator, and (c) constraints to regulate

\footnotetext{
${ }^{39}$ Dayal $(2011,2015)$ argues that Hindi plural forms that pseudo-incorporate do give rise to numberneutral interpretations, but only in atelic or habitual contexts, but not in telic ones. She defends an analysis where atelicity-and not nominal number-enables number neutrality. Atelicity is not a factor in the examples we have considered here, as can be seen, e.g., in the telic examples in (20), (22) or (25) for English, or (34) and (38) for Ljubljana Slovenian, all of which are examples of inclusive plurals.

40 English and Spanish have been argued to have syntactically restricted versions of incorporation (for weak definites in Carlson and Sussman 2005, Carlson 2006 or Aguilar-Guevara and Zwarts 2011; for implicit indefinite objects in Martí 2015; for certain Spanish, and Catalan, bare singulars by Espinal 2010) - but this doesn't explain the data we are after.

${ }^{41}$ It will not do to postulate that English is a [+atomic]-only language, while Slovenian uses [ \pm atomic] (in addition to [ \pm minimal]). That is, it will not do to combine an inclusive-only account for some languages with an ambiguity account for others. That's because, if [+atomic]-only systems are allowed, then the prediction is that there should exist number systems with only one number value, namely, singular, contrary to fact. Thanks to an anonymous reviewer for raising this issue.

${ }^{42}$ Many thanks to Jacopo Romoli for suggesting this option and for discussing it with me.
} 
the distribution of (b) so that exclusive and inclusive plural interpretations are generated in the correct contexts. Because this type of approach essentially replaces [-atomic] with (a), the exhaustivity operator, it is in principle implementable within Harbour's system and not subject to the same criticism that inclusive-only approaches suffer from. The exhaustivity operator is a syntactic object, just like [-atomic]. Mayr makes crucial use of a predicate-level exhaustivity operator for exclusive plural interpretation generation.

Mayr's proposal is compatible with a [+atomic] feature for morphologically singular DPs. In order to make comparison easy with earlier claims above, we can assume that, similarly to inclusive-only accounts, we have the following: 43

(65) a. $[[$ cat $]]=[[+$ atomic $]]([[\mathrm{nP}]])=\lambda \mathrm{x} . \mathrm{x}$ is a cat $\&$ atom $(\mathrm{x})$

b. $[[$ cats $]]=[[\mathrm{nP}]]=\lambda \mathrm{x} . \mathrm{x}$ is a cat

(singular)

(plural)

Because the denotation of the singular form is a subset of the denotation of the plural form, singular and plural stand in a scalar relation, as before. The predicative exhaustivity operator, which I call Exh-pred, is in (66). It makes use of predicate alternatives (cf. Fox 2007, Ivlieva 2013, Spector 2007, Zweig 2009, among many others):

$$
[[\text { Exh-pred }]]=\lambda \mathrm{f}_{\text {et. }} \lambda \mathrm{x} . \mathrm{f}(\mathrm{x})=1 \& \forall \mathrm{g} \in \text { Alt }[\mathrm{f} \nsubseteq \mathrm{g} \rightarrow \mathrm{g}(\mathrm{x})=0]
$$

This operator applies to a predicate and returns true for any individual that makes that predicate true and which makes all non-weaker alternative predicates false. The fact that the denotation of plural forms (cf. (65)b) is weaker than the denotation of alternative, singular forms (cf. (65)a) is crucial in generating a plural inference in examples such as (67):

(67) English

Lina harvested tomatoes

Mayr assumes a silent existential generalized quantifier, 'indef', a distributivity operator, D, and movement of noun phrases above D, the latter two familiar from the literature on distributivity. With these ingredients, the following LF is generated for (67):

(68) [indef [Exh-pred tomatoes]] [D [3 [Lina harvested t $\left.\left.t_{3}\right]\right]$

Applying Exh-pred to the nP tomatoes (cf. (65)b) in (68) yields the set of non-atomic tomato individuals, since these individuals are tomato individuals and they make all non-weaker alternative predicates, that is, the singular, atomic-sensitive tomato ((65)a), false. This is equivalent to the effect that [-atomic] would have here. Indef then existentially quantifies over one of these non-atomic individuals, yielding, as desired, an exclusive plural reading for (67). Thus, (67) is correctly predicted to be incompatible with Lina having harvested just one tomato.

\footnotetext{
${ }^{43}$ Mayr assumes that plural morphology delivers the inclusive interpretation in (65)b, since he assumes it corresponds to Link's (1983) *-operator. In Harbour's framework, such interpretations are always available as the denotation of $\mathrm{nP}$, without the need for the *-operator.
} 
Like NumP in ambiguity accounts, Exh-pred is not always generated when there is a plural form in the structure. There is a second exhaustivity operator, which I call Exhprop, in (69), which is propositional in nature. Whichever one of Exh-prop or Exh-pred yields the strongest possible interpretation is the preferred operator in any given case. Exh-prop will be preferred in downward-entailing environments such as (70):

$$
[[\text { Exh-prop }]]^{\mathrm{w}}=\lambda \mathrm{p}_{\mathrm{st}} \mathrm{p}(\mathrm{w})=1 \& \forall \mathrm{q} \in \operatorname{Alt}[\mathrm{p} \nsubseteq \mathrm{q} \rightarrow \mathrm{q}(\mathrm{w})=0]
$$

(70) English

\section{Lina didn't harvest tomatoes}

Exh-prop asserts a proposition and negates all non-weaker alternatives to it, in parallel fashion to Exh-pred. The LF for (70) with this operator is in (71):

\section{[Exh-prop [not [indef tomatoes [D [3 [Lina harvested t3]]]]}

(71) yields an inclusive plural interpretation, that Lina didn't harvest an atomic or a non-atomic tomato-she harvested no tomato at all. This is so because (71) yields the proposition that Lina didn't harvest any tomato at all (by virtue of the semantics of tomatoes, (65)b), and there is no non-weaker alternative to negate because that is already the strongest possible statement. That the strongest possible statement must be made is involved in blocking the LF in (72) for (67):

\section{[Exh-prop [indef tomatoes [D [3 [Lina harvested $\left.\left.\left.t_{3}\right]\right]\right]$}

Exh-prop in (72) yields the proposition that Lina harvested an atomic or a non-atomic tomato (i.e., one or more tomatoes). There isn't a non-weaker alternative proposition to negate. This result is weaker than what (68) gives rise to and is thus blocked ${ }^{44}$.

If Exh-pred is taken to do the work of [-atomic] in the account of (67) and (70), then Exh-pred must also do the work of [-atomic] in other places where Harbour uses it, e.g., in the generation of duals and paucals. Otherwise, we would run into the overgeneration problem discussed above for some inclusive-only accounts. For a language like Ljubljana Slovenian, this approach allows us to entertain the LFs in (74) and (75) for the sentence in (34), repeated as (73), with a plural form:

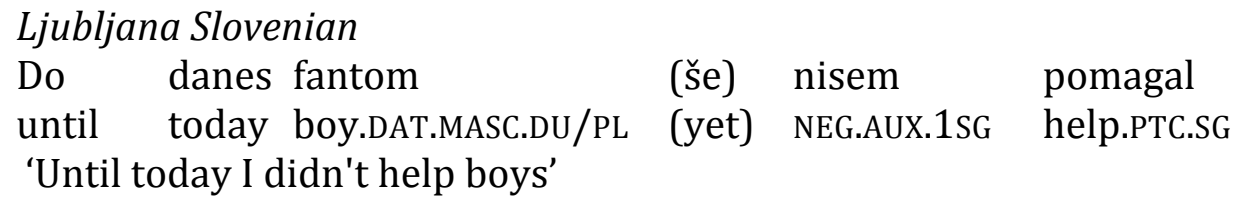

(74) [not [indef [[-minimal [Exh-pred boys]]] [D [3 [I helped $\left.\left.\left.t_{3}\right]\right]\right]$

(75) [Exh-prop [not [indef boys [D [3 [I helped t 3$]]]$

(75) is the chosen representation, as desired. (74) yields the interpretation that there isn't a plurality of three or more boys that I helped ([-minimal [Exh-pred boys]] denotes a set of plural individuals each of which consists of three or more atoms). This is weaker

\footnotetext{
${ }^{44}$ Exh-prop is perhaps a solution to the problem discussed in $\mathrm{ft} .11$, but more needs to be said, as Mayr (2015: 215) acknowledges, about its exact distribution.
} 
than the interpretation that (75) yields, that I didn't help an atomic or a non-atomic boy, an inclusive interpretation, so it is blocked (cf. (71)). In upward-entailing contexts, the LF with Exh-pred delivers the exclusive plural interpretation (i.e., the more than two boys interpretation)(cf. (68)):

(76) [indef [[-minimal [Exh-pred boys]]] [D [3 [I helped t 3$]]]$

This account of exclusive and inclusive plural interpretations in a language with duals is very similar to the one for English given above.

In this system, we can also think of the dual as compositionally built number value, as in Harbour. The building blocks would be [+minimal] plus an additional ingredient that plays a role with plurals, namely, Exh-pred. The structure of a DP with a dual-marked noun could be as follows:

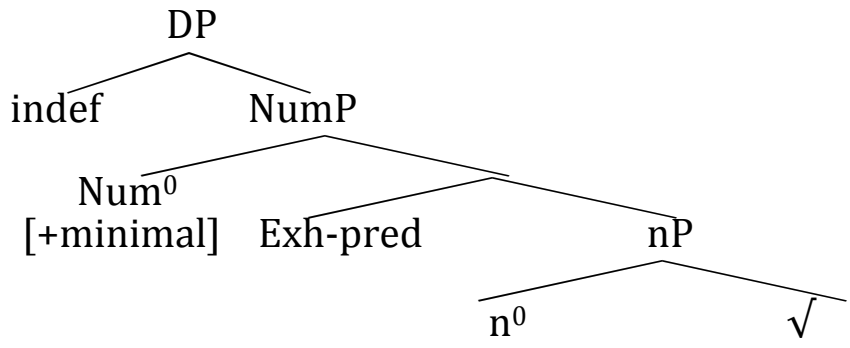

(77) gives rise to the meaning we are after for the dual: [+minimal] selects the minimal individuals, the twosomes, from an already exhaustified set, that is, a set that does not contain atoms. I assume that both [+minimal] and Exh-pred are involved in the morphological spell out of the dual, so that dual forms require the presence of both ${ }^{45}$. This makes the right predictions for sentences in which the dual is negated, as in (35), repeated as (78):

(78) Ljubljana Slovenian

$\begin{array}{llll}\text { Do danes fantoma } & \text { nisem } & \text { pomagal } \\ \text { until today boy.DAT.MASC.DU } & \text { NEG.AUX.1SG } & \text { help.PTC.SG } \\ \text { 'Until today I didn't help (the) two boys' } & \end{array}$

(79) [not [indef [[+minimal [Exh-pred fantoma]]] [D [3 [I helped t 3$]]]$

(79) yields the interpretation that there isn't a duality of boys that I helped (I could have helped, one, or more than two), as desired.

The question arises as to whether it is sensible, from Harbour's perspective, to postulate that [-atomic] may be replaced by Exh-pred in at least some languages. Presumably, singular-plural languages without inclusive plurals would still make use of [ \pm atomic], so the Mayr-based account of the inclusive plurals problem would need to state that either [ \pm atomic] or [+atomic]/Exh-pred systems (and those built of these) are possible. While this state of affairs is indeed a possibility, it nevertheless constitutes a departure from the reasonable hypothesis that the features that are paired are those whose meanings are counterparts of each other (the way Harbour's +/- valued features

45 This assumption, while not attractive, corresponds to the assumption that only plural forms (not duals, paucals, etc.) can be inclusive in the ambiguity account (which is correct, as far as I know). 
are).

In addition, the attachment possibilities of Exh-pred might constitute an issue. A number of attachment sites are available for Exh-pred in the structure of DP, whereas the attachment sites for [-atomic] are in principle constrained by NumP and by the semantics of [-atomic]. (80), for example, yields the wrong result for the dual, since it predicts that a DP with a dual-marked noun could be interpreted as singular, contrary to fact:

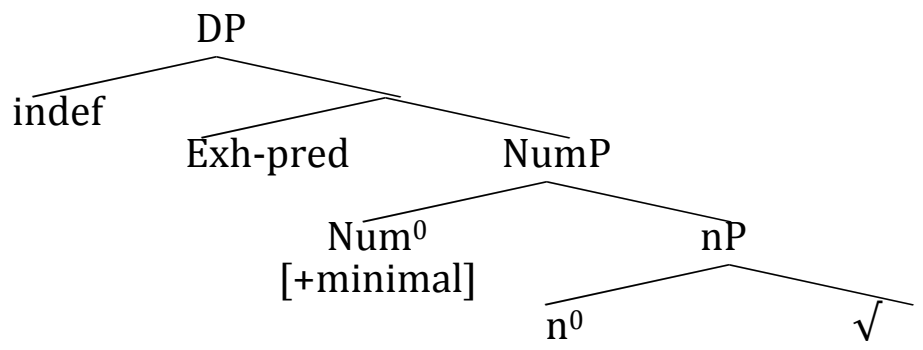

A structure like (80) but with [-atomic] instead of Exh-pred, on the other hand, correctly yields an ill-formed result, as there are no non-atoms in a set of atoms (the latter, what NumP delivers here). In number systems with, in addition, the feature [ \pm additive], or which allow repetition of features, additional possible attachment sites might be available, but not all of them might yield correct results. Finally, if Exh-pred is used elsewhere in the theory to generate scalar implicatures (which is the purpose of postulating exhaustivity operators in the first place), the cross-linguistic typology of number and inclusive plurals would be intimately tied to quite disparate phenomena, with potentially far-reaching consequences for language acquisition and change. This is, in principle an attractive possibility, but a possibility that needs to be properly explored.

Be this as it may, incorporating Mayr's Exh-pred into Harbour's theory to do the work of [-atomic] avoids, like ambiguity approaches, the under- and over-generation problems pointed out earlier for inclusive-only accounts. That's because it is still the case that one of the ingredients of the dual (or the paucal), Exh-pred, is involved in the account of plural forms. The ambiguity of plural forms of ambiguity accounts translates in this account into the possibility to combining them either with Exh-prop (for inclusive interpretations) or with Exh-pred (for exclusive interpretations). Without Exh-pred (see, e.g., Spector 2007), it is no longer possible to compositionally build duals or paucals (since predicate-level features such as [ \pm minimal] cannot operate on what results from applying Exh-prop, and it is difficult to see how a system with propositional-level number features would work), and thus the over-generation problem of section 3.2 resurfaces.

\section{Conclusion}

In this paper I have defended the thesis that an account of both inclusive plurals and the cross-linguistic typology of grammatical number requires the postulation of a [-atomic] feature (or something very much like it, such as Mayr's Exh-pred) in the structure of exclusive plural DPs. The argument was divided into two main parts. First, I showed that accounts of inclusive plurals that derive exclusive plurals without [-atomic] suffer from important under- and over-generation problems. I argued against two versions of the [-atomic]-less exclusive plurals view. If languages with inclusive plurals never make use of [-atomic], we wrongly predict that languages with [-atomic]-based number 
values such as dual or paucal should not have inclusive plurals, a problem of undergeneration. If languages with inclusive plurals use [-atomic] for some number values, just not the plural, these accounts over-generate with respect to the cross-linguistic typology of number, as languages with duals or paucals and no plurals are predicted to exist, contrary to fact. Then, I showed that accounts of inclusive plurals that postulate a [-atomic] feature or Mayr's predicate-level Exh-pred in the structure of exclusive plural DPs do not suffer from these problems.

I have focused exclusively on the semantics of bare plurals in simple contexts. However, it is well-known that the proper explanation of the behavior of plural-marked DPs more generally is by no means trivial (see, e.g., Mayr 2015 for an attempt to explain the behavior of definite plural DPs, and Ivlieva 2013 and Zweig 2009 for attempts to explain dependent plurality). The most natural next step for the line of inquiry investigated above consists, in my view, in exploring how (well) it can be integrated in the account of more complex phenomena involving plural DPs.

The argument proposed here suggests that the accounts of seemingly fully independent phenomena, such as the typology of grammatical number and the distribution of exclusive and inclusive plural DPs, are actually intimately related.

\section{References}

Aguilar-Guevara, Ana, and Joost Zwarts. Weak Definites and Reference to Kinds. 2011. Proceedings of SALT 20, 179-196

Baker, Mark. 1988. Incorporation. A Theory of Grammatical Function Changing. The University of Chicago Press

Bale, Alan, Michaël Gagnon, and Hrayr Khanjian. 2011. On the Relationship between Morphological and Semantic Markedness: The Case of Plural Morphology. Morphology 21, 197-221.

Bale, Alan and Hrayr Khanjian. 2014. Syntactic Complexity and Competition: the Singular-Plural Distinction in Western Armenian. Linguistic Inquiry 45, 1-26

van Benthem, Johan. 1986. Essays in logical semantics. Reidel

Cabredo Hofherr, Patricia. To appear. Nominal Number Morphology. In Patricia Cabredo Hofherr and Jenny Doetjes (eds.) Handbook of Grammatical Number, OUP

Carlson, Gregory. 1977. Reference to Kinds in English. Ph. D. Dissertation, University of Massachusetts at Amherst.

Carlson, Gregory. 2006. The Meaningful Bounds of Incorporation. In Vogeleer and Tasmowski (2006), 35-50

Carlson, Gregory, and Rachel Sussman. 2005. Seemingly Indefinite Definites. In Stephan Kepser and Marga Reis (eds.) Linguistic Evidence: Empirical, Theoretical, and Computational Perspectives 85, 71-85. De Gruyter

Chierchia, Gennaro. 1998a. Plurality of Mass Nouns and the Notion of 'Semantic Parameter'. In Susan Rothstein (ed.), Events and Grammar, 53-103. Dordrecht: Kluwer Academic Publishers.

Chierchia, Gennaro. 1998b. Reference to Kinds across Languages. Natural Language Semantics 6, 339-405

Chierchia, Gennaro, Danny Fox and Benjamin Spector. 2012. The Grammatical View of Scalar Implicatures and the Relationship between Semantics and Pragmatics. In Paul Portner, Claudia Maienborn and Klaus von Heusinger (eds.) Semantics: An International Handbook of Natural Language Meaning, vol. 3, Berlin: Mouton de Gruyter

Corbett, Greville. 2000. Number. Cambridge, UK: Cambridge University Press. 
Corbett, Greville. 2012. Features. Cambridge, UK: Cambridge University Press.

Corbett, Greville and Richard Hayward. 1987. Gender and Number in Bayso. Lingua 73, 1-28

Cyrino, Sonia \& M.Teresa Espinal. 2015. Bare Nominals in Brazilian Portuguese: More on the DP/NP Analysis. Natural Language \& Linguistic Theory 33, 471-521

Dalrymple, Mary, Makoto Kanazawa, Yookyung Kim, Sam Mchombo and Stanley Peters. 1998. Reciprocal expressions and the concept of reciprocity. Linguistics and Philosophy 21: 159-210

Dalrymple, Mary and Suriel Mofu. 2013. Semantics of Number in Biak. Language and Linguistics in Melanesia 31, 42-55

Dayal, Veneeta. 2011. Pseudo Incorporation in Hindi. Natural Language and Linguistic Theory 29, 123-167

Dayal, Vaneeta. 2015. Incorporation: Morpho-Syntactic vs. Semantic Considerations, in Olga Borik and Berit Gehrke (eds.) The Syntax and Semantics of PseudoIncorporation, Syntax and Semantics 40

Derganc, Aleksandra. 2003. The Dual in Slovenian. In Janez Orešnik and Donald D. Reindl (eds.) Slovenian from a Typological Perspective. Berlin: Akademie Verlag, 165-181.

Diver, William 1987. The dual. Columbia University Working Papers in Linguistics 8, 100-14

Dobrovie-Sorin, Carmen, Tonia Bleam, and M. Teresa Espinal. 2006. Bare Nouns, Number and Types of Incorporation. In Vogeleer and Tasmowski (2006), 51-79

Doron, Edit. 2003. Bare Singular Reference to Kinds. In Robert Young and Yuping Zhou (eds.) Proceedings of SALT 13, 73-90.

Dvorak, Bostjan and Uli Sauerland. 2006. The Semantics of the Slovenian Dual. James Lavine, Steven Franks, Mila Tasseva-Kurktchieva and Hana Filip (eds.) Proceedings of FASL 14, 98-112.

Espinal, M. Teresa. 2010. Bare Nominals in Catalan and Spanish. Lingua 120, 984-1009

Everett, Daniel. 1986. Pirahã. Handbook of Amazonian Languages, vol. 1, Desmond C. Derbyshire and Geoffrey K. Pullum (eds.), 200-325. Berlin: Mouton de Gruyter.

Farkas, Donka and Henriëtte de Swart. 2003. The Semantics of Incorporation. Stanford: CSLI Publications

Farkas, Donka and Henriëtte de Swart. 2010. The Semantics and Pragmatics of Plurals. Semantics and Pragmatics 3: 1-54.

Ferreira, Marcelo. 2010. The Morpho-Semantics of Number in Brazilian Portuguese Bare Singulars. Journal of Portuguese Linguistics 9, 95-116.

Fox, Danny. 2007. Free Choice and the Theory of Scalar Implicatures. In Uli Sauerland \& Penka Stateva (eds.), Presuppositions and Implicatures in Compositional Semantics, 71-120.

van Geenhoven, Veerle. 1998. Semantic Incorporation and Indefinite Descriptions. Stanford: CSLI Publications.

van Geenhoven, Veerle. 2000. Pro Properties, Contra Generalized Kinds. In Brendan Jackson and Tanya Matthews (eds.) Proceedings of SALT X, 221- 238, Ithaca, NY: Cornell University

Greenberg, Joseph. 1966. Language Universals, with Special Reference to Feature Hierarchies. The Hague: Janua Linguarum, 59, Mouton.

Greenberg, Joseph. 1972. Numeral Classifiers and Substantival Number: Problems in the Genesis of a Linguistic Type. In Working Papers on Language Universals, 9, 1-39. 
Grimm, Scott. 2012. Plurality is Distinct from Number-Neutrality. Proceedings of NELS 41

Görgülü, Emrah. 2012. Semantics of Nouns and the Specification of Number in Turkish, PhD dissertation, Simon Fraser University

Guerzoni, Elena \& Yael Sharvit. 2007. A Question of Strength: on NPIs in Interrogative Clauses. Linguistics and Philosophy 30, 361-391

Harbour, Daniel. 2011. Descriptive and Explanatory Markedness. Morphology 21, 223245

Harbour, Daniel. 2014. Paucity, Abundance and the Theory of Number. Language 90, 158-229.

Harbour, Daniel. 2016. Impossible Persons. MIT Press

Hayward, Richard. 1979. Bayso Revisited: some Preliminary Linguistic ObservationsII. Bulletin of the School of Oriental and African Studies, University of London 42, 101-32

Herrity, Peter. 2015. Slovene: a Comprehensive Grammar. Routledge

Hoeksema, Jack. 1983. Plurality and Conjunction. In Alice ter Meulen (ed.), Studies in Model-Theoretic Semantics, 63-83. Dordrecht: Foris

Hutchisson, Don. 1986. Sursurunga Pronouns and the Special Uses of Quadral Number. Ursula Wiesemann (ed.), 1-20. Tübingen: Gunter Narr.

Ivlieva, Natalia. 2013. Scalar Implicatures and the Grammar of Plurality and Disjunction, MIT PhD dissertation

Kiparsky, Paul and Judith Tonhauser. 2012. Semantics of Inflection. In Claudia Maienborn, Klaus von Heusinger \& Paul Portner (eds.), Handbook of Semantics, 2070-2097. Berlin: de Gruyter.

Koval', Antonina. 1979. O značenii morfologičeskogo pokazatelja klassa v fula. In N. V. Oxotina (ed.) Morfonologija i morfologija klassov slov v jazykax Afriki, 5-100. Moscow: Nauka.

Krifka, Manfred. 1989. Nominal Reference, Temporal Constitution and Quantification in Event Semantics. In Renate Bartsch, Johan van Benthem \& Peter van Emde Boas (eds.), Semantics and Contextual Expression, Dordrecht

Krifka, Manfred. 1995. Common Nouns: a Contrastive Analysis of Chinese and English. In Greg Carlson and Jeffrey Pelletier (eds.) The Generic Book, Chicago: Chicago University Press, 398-411

Laca, Brenda. 1996. Acerca de la Semántica de los 'Plurales Escuetos' del Español. In Ignacio Bosque (ed.). El Sustantivo Sin Determinación. Madrid: Visor Libros, 241-268

Ladusaw, William. 1996. Negation and Polarity Items. In Shalom Lappin (ed.), The Handbook of Contemporary Semantic Theory, 321-341. Oxford: Blackwell.

Lasersohn, Peter. 1995. Plurality, Conjunction, and Events. Studies in Linguistics and Philosophy 55, Springer

Lasersohn, Peter. 2011. Mass Nouns and Plurals. In Klaus von Heusinger, Claudia Maienborn and Paul Portner (eds.), Semantics: An International Handbook of Natural Language Meaning, vol. 2, 1131-1153. De Gruyter.

Link, Godehard. 1983. The Logical Analysis of Plural and Mass Terms: a LatticeTheoretical Approach. In Rainer Bäuerle, Christoph Schwarze \& Arnim von Stechow (eds.), Meaning, Use and Interpretation of Language, 302-323. Berlin: de Gruyter.

MacDonell, Arthur. 1927. A Sanskrit Grammar for Students. London: Oxford University Press.

Martí, Luisa. 2008. The Semantics of Plural Indefinites in Spanish and Portuguese. Natural Language Semantics 16, 1-37. 
Martí, Luisa. 2015. Grammar vs. Pragmatics: Carving Nature at the Joints. Mind and Language 30, 437-473

Martí, Luisa. 2017. [ \pm Atomic]. Talk presented at the $27^{\text {th }}$ Colloquium on Generative Grammar, Universidad de Alcalá, Madrid, Spain.

Marušič, Lanko and Rok Žaucer. to appear. Case Study: Slovenian Dual. In Patricia Cabredo Hofherr and Jenny Doetjes (eds.) Handbook of Grammatical Number, OUP

Massam, Diane. 2001. Pseudo Incorporation in Niuean. Natural Language and Linguistic Theory 19, 153-197

Mayr, Clemens. 2015. Plural Definite NPs Presuppose Multiplicity via Embedded Exhaustification. SALT 25, 204-224

McNally, Louise. 1995/2004. Bare Plurals in Spanish are Interpreted as Properties. Catalan Journal of Linguistics 3, 115-133

Mithun, Marianne. 1984: The Evolution of Noun Incorporation. Language, 60, 847-94.

Mithun, Marianne. 1986: On the Nature of Noun Incorporation. Language, 62, 32-7.

Müller, Anna. 2002. Genericity and the Denotation of Common Nouns in Brazilian Portuguese. Probus 2, 279-298.

McKay, Graham. 1978. Pronominal person and number categories in Rembarrnga and Djeebbana. Oceanic Linguistics 17, 27-37

Nevins, Andrew. 2011. Marked Targets vs. Marked Triggers and Impoverishment of the Dual. Linguistic Inquiry 42, 413-444

Noyer, Rolf. 1992. Features, positions and affixes in autonomous morphological structure. PhD dissertation, MIT

Pereltsvaig, Asya. 2014. On Number and Numberlessness in Languages with and without Articles. In Patricia Cabredo-Hofherr and Anne Zribi-Hertz (eds.) Crosslinguistic Studies on Noun Phrase Structure and Reference, Brill: Leiden and Boston, 52-73

Plank, Frans. 1995. Domains of the Dual, in Maltese and in General. Rivista di Linguistica 8, 123-140

Pires de Oliveira, Roberta and Susan Rothstein. 2011. Bare Singular Noun Phrases are Mass in Brazilian Portuguese. Lingua 121: 2153-2175

Polinsky, Maria. 1990. Subject Incorporation: Evidence from Chukchee. In K. Dziwirek, P. Farrell, and E. Mejfas-Bikandi (eds.), Grammatical Relations: A Cross Theoretical Perspective. Stanford, CA: Center for the Study of Language and Information, 349-64

Renans, Agata, George Tsoulas, Raffaella Folli, Nihan Ketrez, Lyn Tieu, Hanna de Vries, and Jacopo Romoli. 2017. Turkish Plural Nouns are Number-Neutral: Experimental Data, Proceedings of the $21^{\text {st }}$ Amsterdam Colloquium, 365-374.

Rothstein, Susan. 2010. Counting and the Mass-Count Distinction. Journal of Semantics 27, 343-397.

Sağ, Yağmur. 2016. On the Semantics of Classifiers: a New Perspective from an Optional Classifier Language, Turkish. http://ling.auf.net/lingbuzz/002999

Sağ, Yağmur. 2017. The Semantics of Numeral Constructions in Turkish. Sinn und Bedeutung 22.

Sanches, Mary. 1973. Numerical Classifiers and Plural Marking: an Implicational Universal. In Working Papers on Language Universals 11, 3-22. Language Universals Project. Stanford, CA.

Sauerland, Uli. 2003. A New Semantics for Number. In Rob Young \& Yuping Zhou (eds.), Semantics and Linguistic Theory (SALT), 13, 258-275. Ithaca, N.Y: Cornell University CLC-Publications.

Sauerland, Uli. 2005. The Epistemic Step. Experimental Pragmatics, Cambridge 
University

Sauerland, Uli, Jan Anderssen and Kazuko Yatsushiro. 2005. The Plural is Semantically Unmarked. In Stefan Kepser and Marga Reis (eds.), Linguistic Evidence, 409-30. de Gruyter.

Munn, Alan, and Cristina Schmitt. 2005. Number and Indefinites. Lingua 115, 821-855.

Schwarzschild, Roger. 1996. Pluralities. Dordrecht: Kluwer Academic Publishers.

Spector, Benjamin. 2007. Aspects of the Pragmatics of Plural Morphology: on HigherOrder Implicatures. In Uli Sauerland \& Penka Stateva (eds.), Presuppositions and Implicatures in Compositional Semantics, 243-281.

Toporišič, Jože. 2000. Slovenska slovnica. Maribor: Obzorja.

Toporišič, Jože et al. 2001. Slovenski pravopis. Ljubljana: Založba ZRC.

Vogeleer, Svetlana \& Liliane Tasmowski. 2006. Non-definiteness and Plurality. John Benjamins, Amsterdam.

Wilhelm, Andrea. 2008. Bare Nouns and Number in Dëne Sųłiné. Natural Language Semantics 16, 39-68

Yatsushiro, Kazuko, Uli Sauerland \& Artemis Alexiadou. 2017. The Unmarkedness of Plural: Crosslinguistic Data. In Maria LaMendola \& Jennifer Scott, BUCLD 41: Proceedings of the 41st annual Boston University Conference on Language Development, 753-765. Somerville, USA: Cascadilla.

Zweig, Eytan. 2009. Number-Neutral Bare Plurals and the Multiplicity Implicature. Linguistics and Philosophy 32, 353-407 